\title{
Repurposing the NRF2 Activator Dimethyl Fumarate as Therapy Against Synucleinopathy in Parkinson's Disease
}

\author{
Isabel Lastres-Becker,, ${ }^{1,2}$ Angel J. García-Yagüe,, Robert H. Scannevin, María J. Casarejos, \\ Sebastian Kügler, Alberto Rábano, and Antonio Cuadrado ${ }^{1,2}$
}

\begin{abstract}
Aims: This preclinical study was aimed at determining whether pharmacological targeting of transcription factor NRF2, a master controller of many homeostatic genes, might provide a disease-modifying therapy in the animal model of Parkinson's disease (PD) that best reproduces the main hallmark of this pathology, that is, $\alpha$-synucleinopathy, and associated events, including nigral dopaminergic cell death, oxidative stress, and neuroinflammation. Results: Pharmacological activation of NRF2 was achieved at the basal ganglia by repurposing dimethyl fumarate (DMF), a drug already in use for the treatment of multiple sclerosis. Daily oral gavage of DMF protected nigral dopaminergic neurons against $\alpha$-SYN toxicity and decreased astrocytosis and microgliosis after 1,3, and 8 weeks from stereotaxic delivery to the ventral midbrain of recombinant adeno-associated viral vector expressing human $\alpha$-synuclein. This protective effect was not observed in Nrf2-knockout mice. In vitro studies indicated that this neuroprotective effect was correlated with altered regulation of autophagy markers SQTSM1/p62 and LC3 in MN9D, BV2, and IMA 2.1 and with a shift in microglial dynamics toward a less pro-inflammatory and a more wound-healing phenotype. In postmortem samples of PD patients, the cytoprotective proteins associated with NRF2 expression, NQO1 and p62, were partly sequestered in Lewy bodies, suggesting impaired neuroprotective capacity of the NRF2 signature. Innovation: These experiments provide a compelling rationale for targeting NRF2 with DMF as a therapeutic strategy to reinforce endogenous brain defense mechanisms against PD-associated synucleinopathy. Conclusion: DMF is ready for clinical validation in PD. Antioxid. Redox Signal. 25, 61-77.
\end{abstract}

\section{Introduction}

$\mathbf{C}$ URRENT THERAPIES For PARKINSON's Disease (PD) are symptomatic and do not stop the progressive loss of DA neurons (14). In search for a good therapeutic target that could prevent disease progression, in recent years, the antioxidant pathway controlled by transcription factor Nuclear factor (erythroid-derived 2)-like 2 (here termed NRF2 for the protein) has offered new hope (77). NRF2 regulates the expression of about $1 \%$ of human genes, which contain in their promoter regulatory regions an enhancer sequence termed Antioxidant Response Element (60). These genes encode a large variety of cytoprotective proteins that ensure cellular tolerance to multiple stressors by participating in biotransformation, antioxidant reactions, and inflammation, and by modifying the cellular metabolic program (27). Circumstantial

Innovation
Transcription factor NRF2, a master regulator of redox
homeostasis, provides additional protection against $\alpha$ -
synuclein proteinopathy in Parkinson's disease. The re-
purposing of dimethyl fumarate (Tecfidera) to target NRF2 in
the brain offers a compelling rationale to start clinical trials.

\footnotetext{
${ }^{1}$ Centro de Investigación Biomédica en Red sobre Enfermedades Neurodegenerativas (CIBERNED), Instituto de Investigación Sanitaria La Paz (IdiPaz), Instituto de Investigaciones Biomédicas Alberto Sols UAM-CSIC, Madrid, Spain.

${ }^{2}$ Department of Biochemistry, Faculty of Medicine, Autonomous University of Madrid, Madrid, Spain.

${ }^{3}$ Biogen, Neurology Research, Cambridge, Massachusetts.

${ }^{4}$ Servicio de Neurobiología-Investigación, Instituto Ramón y Cajal de Investigación Sanitaria (IRYCIS), Madrid, Spain.

${ }^{5}$ Department of Neurology, Center Nanoscale Microscopy and Molecular Physiology of the Brain (CNMPB), University Medicine Göttingen, Göttingen, Germany.

${ }^{6}$ Department of Neuropathology and Tissue Bank, Unidad de Investigación Proyecto Alzheimer, Fundación CIEN, Instituto de Salud Carlos III, Madrid, Spain.
} 
evidence connects loss of NRF2 with PD. Thus, NRF2 activity declines with aging, which is the main risk factor for PD. In nigral dopaminergic neurons, NRF2 is located in the cytosol, whereas in age-matched PD patients, it is found in the nucleus (54) and the NRF2 signature, represented by expression of NADPH quinone oxidoreductase 1 (NQO1) (70), and heme oxygenase-1 (HO-1) $(13,45,61,78)$ is upregulated, suggesting an attempt of brain protection through this pathway (16). Probably, the most compelling evidence comes from the genetic associations showing that a functional haplotype in the human NFE2L2 gene promoter (here termed Nrf2 for the mouse gene), which confers slightly increased transcriptional activity, is associated with decreased risk and delayed onset of $\mathrm{PD}(71,72)$.

The main mechanism to control NRF2 is at the level of protein stability by the ubiquitin E3 ligase adapter KEAP1 (49). This protein contains several cysteine residues that are capable of undergoing redox modifications and adduct formation with electrophilic compounds. Therefore, NRF2 levels can be modulated pharmacologically to phenocopy this protective NRF2 haplotype. A protective role of NRF2 has been suggested in several cellular and animal models of PD, based on intoxication with mitochondrial complex I inhibitors that induce oxidative stress and ATP depletion $(5,17$, $34,39,55)$. Conversely, pharmacological induction of NRF2 protected the brain against these toxins $(12,34,35,39,68)$. An important example of these studies is the recent observation that activating NRF2 with dimethyl fumarate (DMF) attenuated oxidative stress and was neuroprotective against 6-hydroxydopamine-induced striatal oxidative stress (35). These results, though promising, would be somewhat expected, that is, boosting the cellular antioxidant capacity by targeting NRF2 should provide protection against toxins that induce oxidative stress. Even if this outcome is expected, the usefulness of NRF2, merely considered as antioxidant target, is not clear in humans, because simple antioxidant therapies such as tocopherol or Coenzyme Q10 supplements have provided little benefit or even deleterious effects. One example is the QE3 phase 3 trial for PD, which showed no evidence of clinical benefit (50). Therefore, to provide compelling preclinical evidence that NRF2 is a valid target to slow or prevent PD progression, it is necessary to determine its protective effect in an animal model that better replicates the human pathology, and this requires addressing the proteinopathy associated with human PD, that is the $\alpha$ synucleinopathy. Attempts to study the $N r f 2$ signature in transgenic mice expressing human $\alpha$-SYN have been inconclusive, because either $\alpha$-SYN pathology was not reproduced in the basal ganglia (24) or there was not a clear loss of nigral dopaminergic neurons and the early expression of Nrf2regulated genes was followed by loss of induction (4). By contrast, we have been using an $\alpha$-synucleinopathy model based on stereotaxic delivery of pseudotype 6 recombinant adeno-associated vector (rAAV-6- $\alpha-S Y N$ ) to the ventral midbrain (VMB) that replicates $\alpha-S Y N$ aggregates and dystrophic Lewy neurites (45). With this model, we reported that NRF2 deficiency aggravates protein aggregation, neuronal death, and inflammation in early-stage PD. Those experiments provided a new scenario to validate NRF2 as a new target for PD in a more meaningful preclinical setting.

A wealth of NRF2 activators has been identified that appear to disrupt the KEAP1/NRF2 interaction (28). However, from the point of view of a potential brain therapy, only three compounds have consistently demonstrated sufficient pharmacokinetic and pharmacodynamic properties to act in this tissue: sulforaphane (22), CDDO-methyl ester (also known as bardoxolone methyl) (73), and DMF. The most successful case reported so far in targeting NRF2 is this dimethyl ester derivative of fumaric acid. DMF crosses the gastrointestinal barrier, after which it is converted into monomethyl fumarate (MMF) (58). In theory, the esterase end-product is fumarate but it is not detectable in plasma, suggesting that the TCA cycle is capable of rapidly processing any fumarate that forms from $\mathrm{DMF} / \mathrm{MMF}$. Both $\mathrm{DMF}$ and $\mathrm{MMF}$ (and fumarate if it were present) covalently modify KEAP1, which results in an accumulation of NRF2, leading to up-regulation of the transcriptional NRF2 signature (11). The immune modulatory effect of DMF has been exploited for other autoimmune diseases such as psoriasis (2), lupus erythematosus (69), asthma, and arthritis (63). Very importantly, DMF is an approved drug for relapsing-remitting multiple sclerosis as an oral formulation termed BG-12. After the success with BG-12 in two clinical trials, CONFIRM and DEFINE, this formulation has been commercialized with the name of Tecfidera by Biogen (6), becoming one of the most successful drugs ever developed by the biopharmaceutical industry.

In this study, we aimed at analyzing whether DMF could be used for PD therapy in a murine model of $\alpha$-synucleinopathy and the mechanisms of action. Our results indicate that DMF targets NRF2 at the basal ganglia and exerts a very significant brain protective effect against $\alpha$-SYN toxicity by both activating autophagy and modulating neuroinflammation.

\section{Results}

\section{Oral administration DMF induces the NRF2} signature in the brain

We performed a small pharmacodynamic assay to confirm that DMF crosses the blood-brain barrier and activates NRF2 in the brain. As a control, we used kidneys from the same mice (Supplementary Fig. S1; Supplementary Data are available online at www.liebertpub.com/ars). Following $4 \mathrm{~h}$ after oral administration of 100 or $300 \mathrm{mg} / \mathrm{kg}$ DMF, NRF2 protein levels were slightly increased in the cortex of $\mathrm{Nrf}^{+/+}$ mice (Fig. 1A, B), whereas Nrf2 mRNA levels were unchanged (Fig. 1C), in agreement with the concept that DMF induces the stabilization of NRF2 protein by disrupting its interaction with KEAP1 (11). Regarding NRF2-regulated genes, we found a statistically significant dose-dependent increase in the expression of Nqo1, Osgin1, and Hmoxl in the cortex (two- to three-fold) and STR (1.2-1.8-fold) for $\mathrm{Nrf2}^{+/+}$ mice, and this effect was either very low or undetectable in $N r f 2^{-1-}$ mice (Fig. 1D, E). These effects were more robust in the kidney (Supplementary Fig. S1), but, considering that we did not want to overload the peripheral organs with too much NRF2 induction that could lead to toxic effects, the following experiments were done with the $100 \mathrm{mg} / \mathrm{kg}$ dose (see Discussion section).

\section{Induction of NRF2 signature in the brain by DMF evokes neuroprotective effects in a PD mouse model}

We used an in vivo multifactorial model of $\mathrm{PD}$, based on stereotaxic delivery of an rAAV6- $\alpha-S Y N$ viral vector (67) at 
A DMF

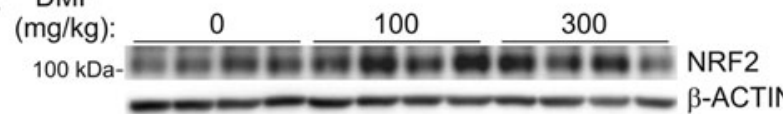

B
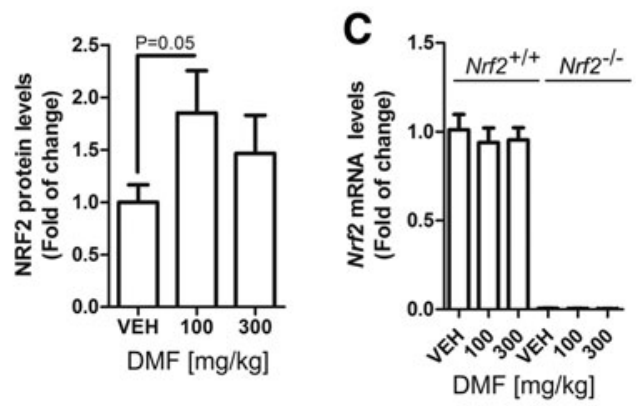

D
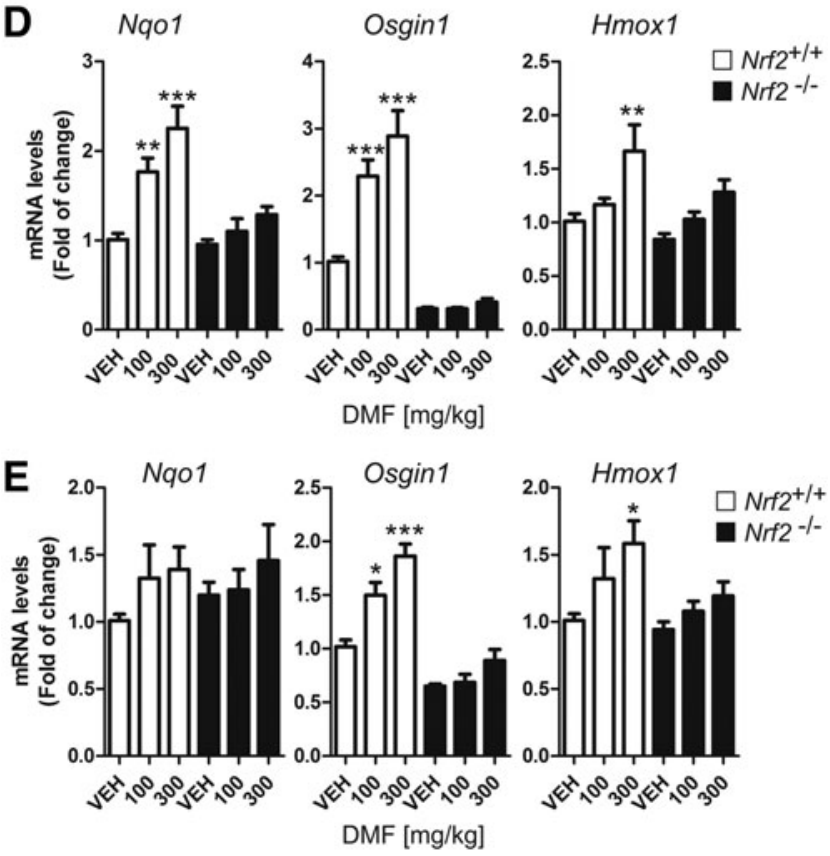

FIG. 1. Induction of NRF2 signature by DMF. Mice received $100 \mathrm{mg} / \mathrm{kg}$ or $300 \mathrm{mg} / \mathrm{kg}$ intragastric doses of DMF and were sacrificed $4 \mathrm{~h}$ later ( $n=4$ animals per group). (A) NRF2 protein levels in cortex: upper panel, anti-NRF2 antibody (note apparent MW slightly higher than $100 \mathrm{kDa}$ ); lower panel, anti- $\beta$-actin antibody. (B) densitometric quantification of protein levels from representative immunoblots of A. (C) qRT-PCR determination of mRNA levels of $N r f 2$ in $\mathrm{Nrf}^{+/+}$and $N r f 2^{-l-}$ mice as indicated. (D, E) qRT-PCR determination of mRNA levels of NRF2-regulated genes Nqo1, Osgin1, and Hmoxl (coding HO-1), respectively, normalized by $\beta$-actin in the cortex and STR, respectively. One-way ANOVA followed by Newman-Keuls post-test was used to assess significant differences among groups. Asterisks denote significant differences with $* p<0.05$, **p $<0.01$, and $* * * p<0.001$ comparing the indicated groups. DMF, dimethyl fumarate; qRT-PCR, quantitative real-time polymerase chain reaction.

the VMB of $\mathrm{Nrf}^{+/+}$and $\mathrm{Nrf} \mathrm{2}^{-/-}$mice (45). A control rAAV6 vector expressing GFP did not have any significant effect on neuron viability, gliosis, or inflammation (45). DMF $(100 \mathrm{mg} / \mathrm{kg}$ ) was administered daily by oral gavage for 1 and 3 weeks, and every other day for 8 weeks (Fig. 2A) after stereotaxic injection. One day before sacrifice, animals were evaluated with a double-blind protocol for motor asymmetry based on the elevated body swing test (Fig. 2B). During the whole time course, vehicle-treated $\mathrm{Nrf} 2^{-/-}$animals presented increased contralateral body torsion compared with $\mathrm{Nrf}^{+/+}$ mice. Very importantly, DMF prevented this behavioral alteration in $\mathrm{Nrf} 2^{+/+}$but had a minor nonstatistically significant effect in $\mathrm{Nrf}^{-/-}$mice. The alteration in motor performance predicted two important findings that would be confirmed later by immunohistochemistry: (i) The extent of the dopaminergic lesion would be large enough to manifest motor alterations; (ii) DMF might be preventing, at least in part, the motor deficit in $\mathrm{Nrf2}^{+/+}$mice but not in $\mathrm{Nrf2^{-/- }}$ mice.

To confirm proper stereotaxic delivery and expression of the rAAV6- $\alpha$-SYN vector to the basal ganglia, $30 \mu \mathrm{m}$-thick sections from STR and VMB were stained with an antibody that was specific for human $\alpha-S Y N$ (Fig. 2C-E). In most animals, the needle tract was observed in the precise position, reaching the substantia nigra $(\mathrm{SN})$, and some scattered neurons were found to express $\alpha-\mathrm{SYN}$ along the needle tract or close to it, indicating proper delivery of the viral vector. Animals with mislocated injections were discarded. After 1 week from infection, the SN of all animals expressed human $\alpha-S Y N$, and the expression in DMF-treated $\mathrm{Nrf}^{+/+}$mice was the strongest. However, at 3 and 8 weeks, only DMF-treated $N r f 2^{+/+}$mice still supported a significant number of neurons expressing $\alpha$-SYN, therefore suggesting that they could tolerate $\alpha-S Y N$ toxicity better than the other experimental settings.

To correlate putative effects of $\alpha$-SYN toxicity with dopaminergic neuron death, parallel series of $30 \mu \mathrm{m}$-thick coronal sections were processed with anti-tyrosine hydroxylase (TH) antibody to assess loss of dopaminergic neuron bodies in SN (Fig. 3A) and fibers in STR (Supplementary Fig. S2). Stereological counting indicated that $\mathrm{TH}^{+}$neurons of $\mathrm{Nrf}^{+/+}$. $\mathrm{VEH}, \mathrm{Nrf} 2^{-/-} \mathrm{VEH}$, and $\mathrm{Nrf} 2^{-/-} \mathrm{DMF}$ groups were partially lost at postinfection week $1(\sim 50 \%)$ and progressed through weeks 3 and $8(\sim 75-80 \%)$ (Fig. 3B). Similarly, $\alpha-S Y N$ overexpression induced a depletion of $\mathrm{TH}^{+}$terminals at the STR, in a time-dependent fashion in vehicle- and DMFtreated $\mathrm{Nrf}^{-1-}$ mice (Supplementary Fig. S2A, B). More importantly, the dopaminergic neuron loss was greatly attenuated in $\mathrm{Nrf}^{+/+}$mice treated with DMF (about $75 \%$ of neurons preserved). In the $\alpha$-SYN-expressing side of the STR (ipsilateral side), the dopamine (DA) and 3,4dihydroxyphenylacetic acid (DOPAC) levels were significantly decreased at 3 weeks in vehicle-treated $N r f 2^{+/+}$mice but DMF attenuated these neurotransmitter changes (Supplementary Fig. S2C). Consistently, DMF increased Nqol and Osgin $1 \mathrm{mRNA}$ expression at the VMB of $\mathrm{Nrf} 2^{+/+}$but not $\mathrm{Nrf} 2^{-/-}$ mice (Fig. 3C, D, respectively). Osgin1 mRNA levels were also increased by $\alpha-S Y N$ expression even in the absence of DMF, suggesting additional mechanisms of regulation for this gene. Taken together, the results shown in Figures 2 and 3 indicate that DMF elicits a protective defense against $\alpha-S Y N$ overexpression and that this effect is mediated through NRF2.

\section{DMF treatment decreased $\alpha-S Y N$-induced astrocytosis and microgliosis}

A distinctive hallmark of PD is the presence of low-grade chronic inflammation that is characterized by microgliosis 
A AAV6- $\alpha-S Y N$

DMF

$\stackrel{\text { every day }}{\longrightarrow} 1$ week

DMF every day 3 weeks

DMF every two days

8 weeks

B
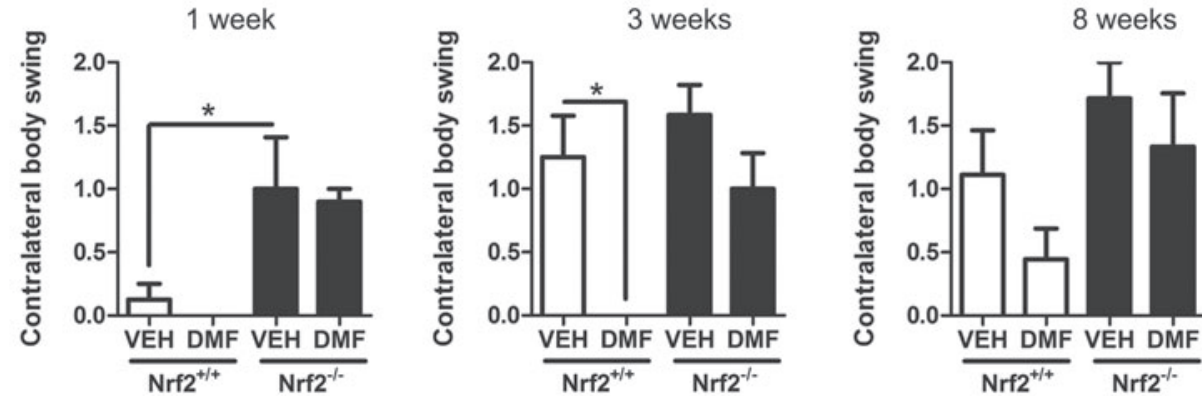

C

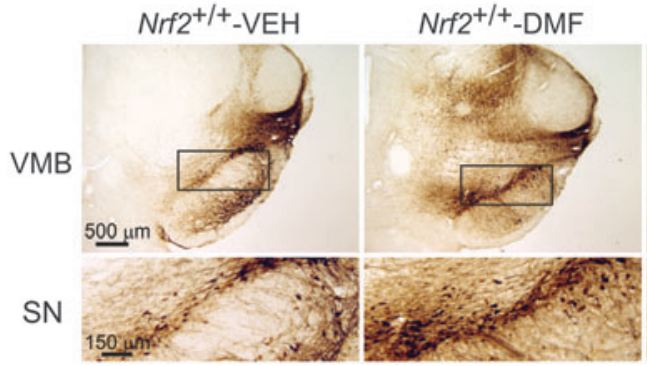

Nrf2-l--VEH

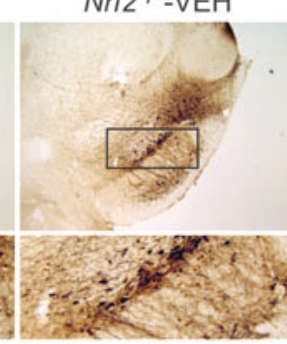

Nrf2-/--DMF

D

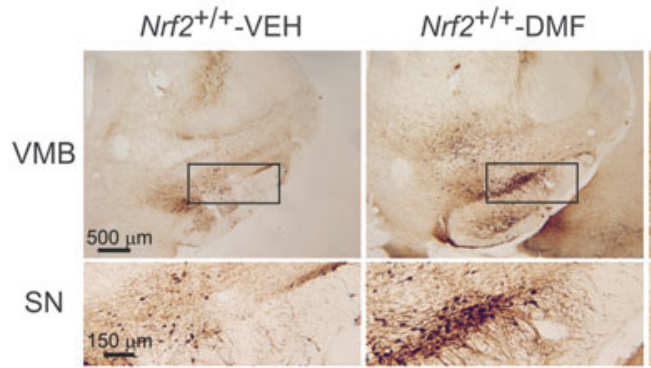

Nrf2-l--VEH

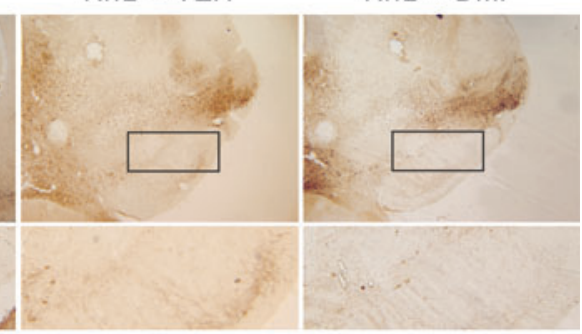

E

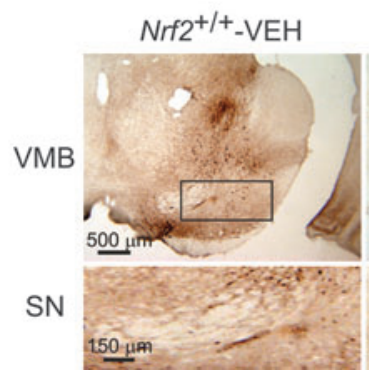

$\mathrm{Nrf2}^{+/+}$-DMF

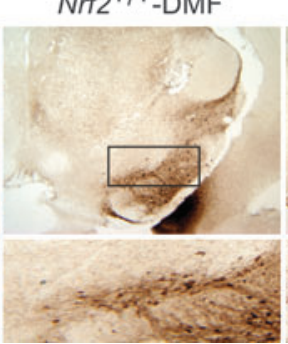

Nrf2-l--VEH

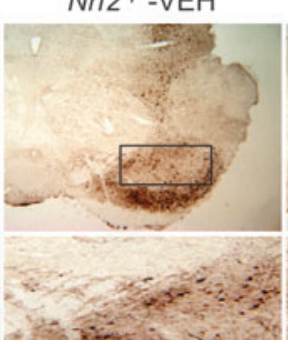

Nrf2-l--DMF

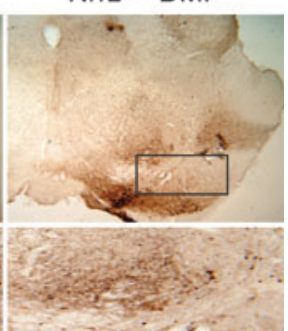

FIG. 2. Motor disturbance and expression of human $\alpha$ $\mathrm{SYN}$ in $\mathrm{Nrf2}^{+/+}$and $\mathrm{Nrf2}^{-/-}$ mice injected with rAAV6$\alpha-S Y N$. (A) schematic diagram of treatments. Animals were injected with rAAV6- $\alpha-$ SYN and treated with DMF daily for 1 or 3 weeks or every other day for 8 weeks. (B) motor analysis of elevated body swing test at 1,3 , and 8 weeks. Asterisks denote significant differences with $* p<$ 0.05 according to a Student's $t$-test $(n=5-7$ animals per group). (C-E) immunohistochemistry with anti-human $\alpha-S Y N$ antibody. Panels correspond to animals stereotaxically injected in the right side of the ventral midbrain with rAAV6- $\alpha-S Y N$ expression vector, treated as indicated in (A), and sacrificed after 1 week (C), 3 weeks (D), and 8 weeks (E). Upper pan$e l$, right side of the $\mathrm{VMB}$; lower panel, high magnification showing the SN. SN, substantia nigra; VMB, ventral midbrain. To see this illustration in color, the reader is referred to the web version of this article at www .liebertpub.com/ars and astrocytosis at the basal ganglia. Therefore, our next step was to evaluate whether DMF could modulate the gliosis triggered by $\alpha$-SYN expression. Regarding astrocytosis, $\alpha$ SYN toxicity correlated with a very significant increase in $\mathrm{GFAP}^{+}$astrocytes at the ipsilateral VMB side of $\mathrm{Nrf}^{+/+}$mice, with a maximum at 3 weeks after infection, and an astrocyte scar remained visible at 3 and 8 weeks (Fig. 4). Importantly, DMF reduced astrogliosis in $N r f 2^{+/+}$mice, with a slight effect in $N r f 2^{-/-}$mice. Similarly, the astrogliosis observed in the ipsilateral STR for vehicle-treated $\mathrm{Nrf2}^{+/+}$was abolished in the DMF-treated $\mathrm{Nrf}^{+/+}$, without any effect in $\mathrm{Nrf2^{-/- }}$ mice (Supplementary Fig. S3). Considering the crucial role of astrocytes in filling gaps left by dead neurons, these results further complement the observations of Figures 2 and 3, indicating that DMF attenuates neuronal death caused by $\alpha$ SYN toxicity.

Regarding microglia, Iba1 immunohistochemistry showed that $\alpha$-SYN expression induced microgliosis at the ipsilateral 


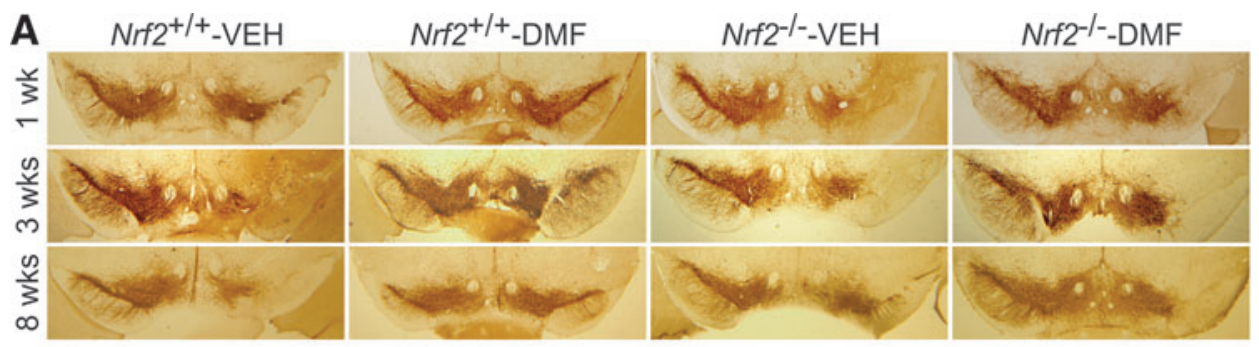

FIG. 3. Neuroprotective effect of DMF. (A) representative immunohistochemistry of dopaminergic neurons, detected with anti-TH antibody. (B) stereological counting of $\mathrm{TH}^{+}$nigral dopaminergic neurons $(n=4-6$ animals per group) after 1,3 , and 8 weeks as indicated in the control side (contralateral, empty boxes) versus the injected side (ipsilateral, filled boxes). (C, D) qRT-PCR determination of mRNA levels for Nqol (C) and Osginl (D) in the contralateral and ipsilateral sides of the VMB. Oneway ANOVA followed by Newman-Keuls post-test was used to assess significant differences among groups. Asterisks denote significant differences $* p<0.05$, $* * p<$ 0.01 , and $* * * \quad p<0.001$ comparing the indicated groups and ${ }^{\#} p<0.01$ and ${ }^{++} p<0.01$ with respect to the $\mathrm{Nrf2}^{+/+}$. VEH contralateral group. TH, tyrosine hydroxylase. To see this illustration in color, the reader is referred to the web version of this article at www .liebertpub.com/ars
B
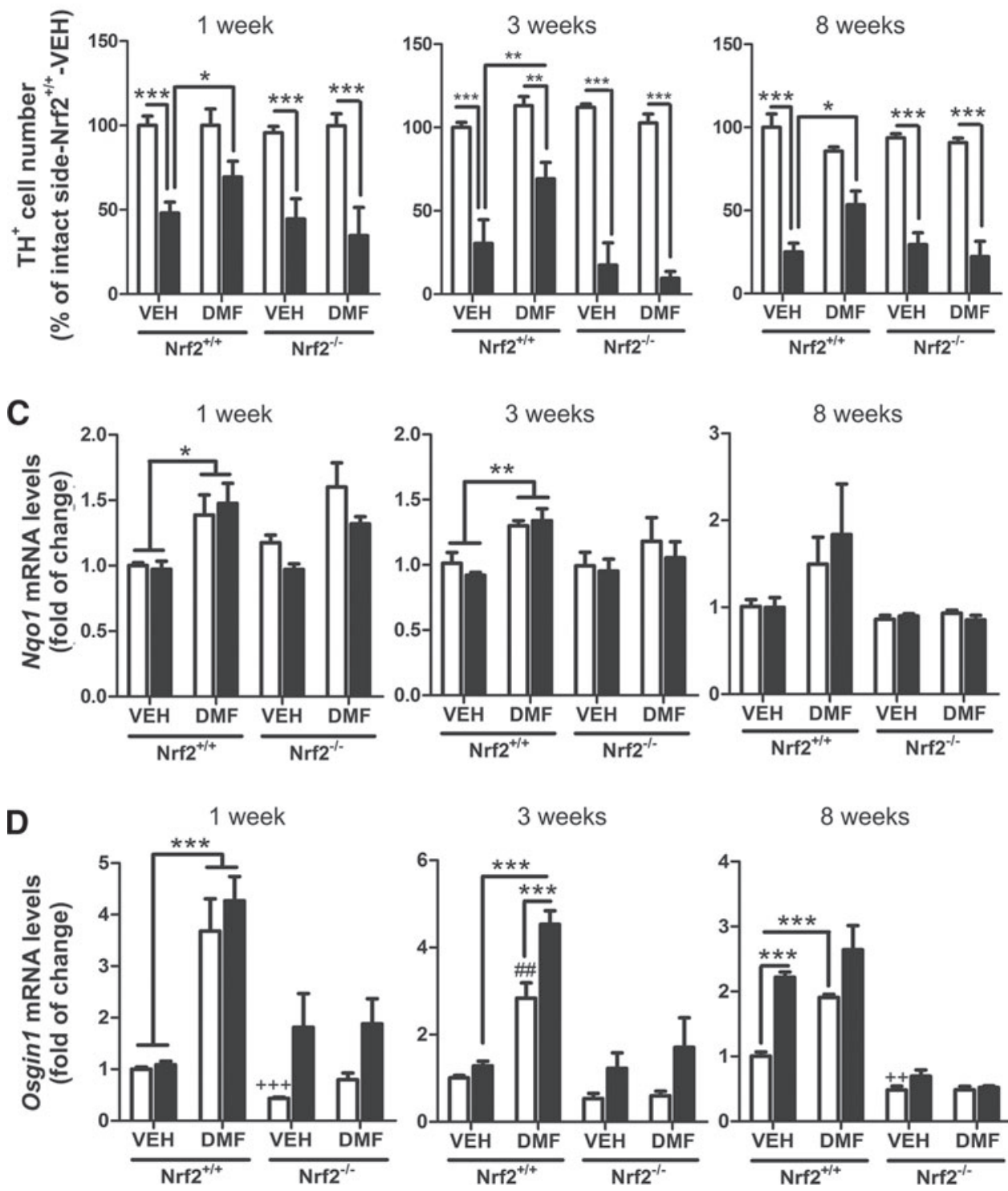

3 weeks

8 weeks
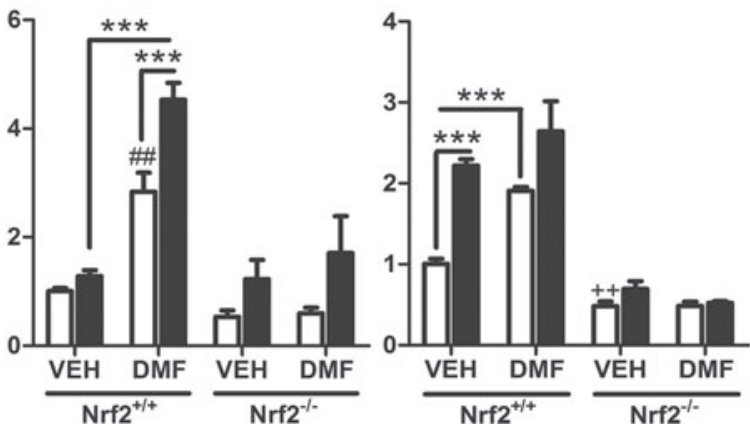

side of vehicle-treated $\mathrm{Nrf}^{+/+}$and $\mathrm{Nrf}^{-/-}$mice after 1 week, reached a maximum after 3 weeks, and returned to close to basal levels at 8 weeks (Fig. 5), indicating that events related to microglial activation took place several weeks before this later time point. However, DMF greatly ameliorated the microgliosis of $\mathrm{Nrf}^{+/+}$and had a minor effect on $\mathrm{Nrf2^{-/ }}$ mice, suggesting that this cell type is very sensitive to NRF2 activation. In the STR, we did not observe microgliosis in the ipsilateral side at any time after $\alpha-S Y N$ injection (Supplementary Fig. S4).
Modulation of classic versus alternative microglial phenotype by DMF

According to their activation state, microglia express specific classical pro-inflammatory (iNOS; IL-1 $\beta$ ), antiinflammatory (IL-4), or type II-deactivating (SPHK1/2) phenotypic markers (18). BV2 microglial cells treated with DMF $(20 \mu M)$ expressed increased mRNA levels of IL-4 and sphingosine-kinase 2 (SPHK2) in a time-dependent manner (Fig. 6A), whereas SPHK1 levels were undetectable (data not 
A

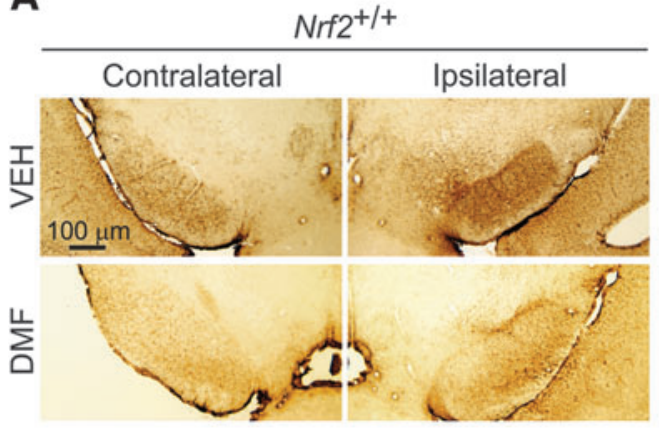

B

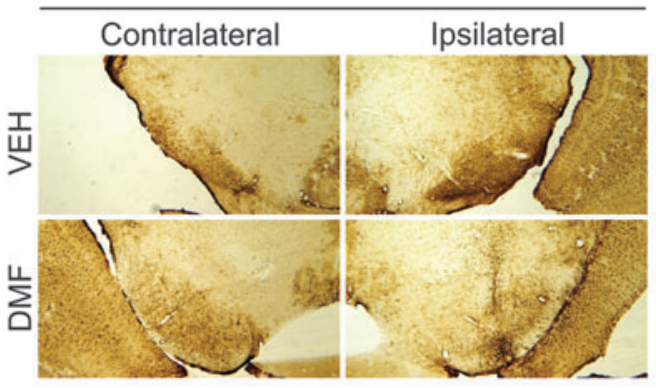

C

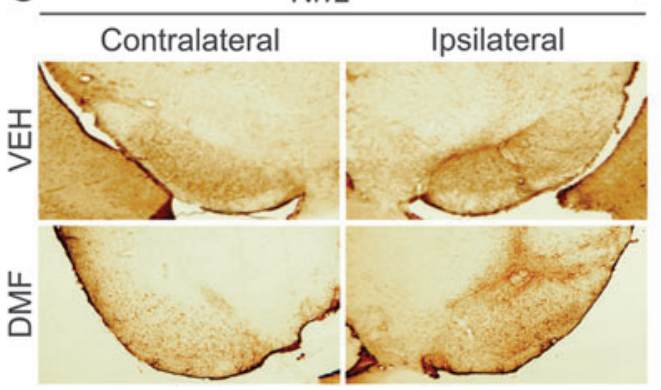

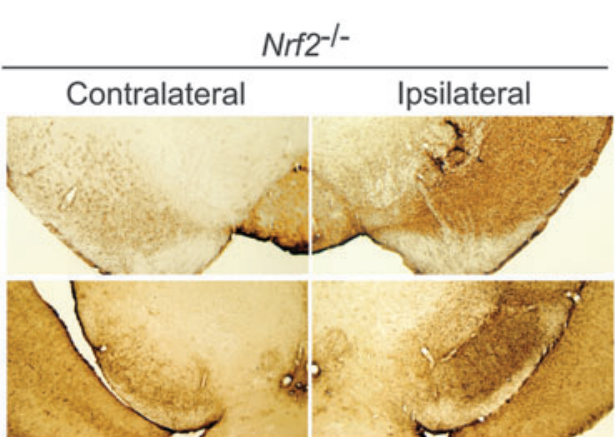
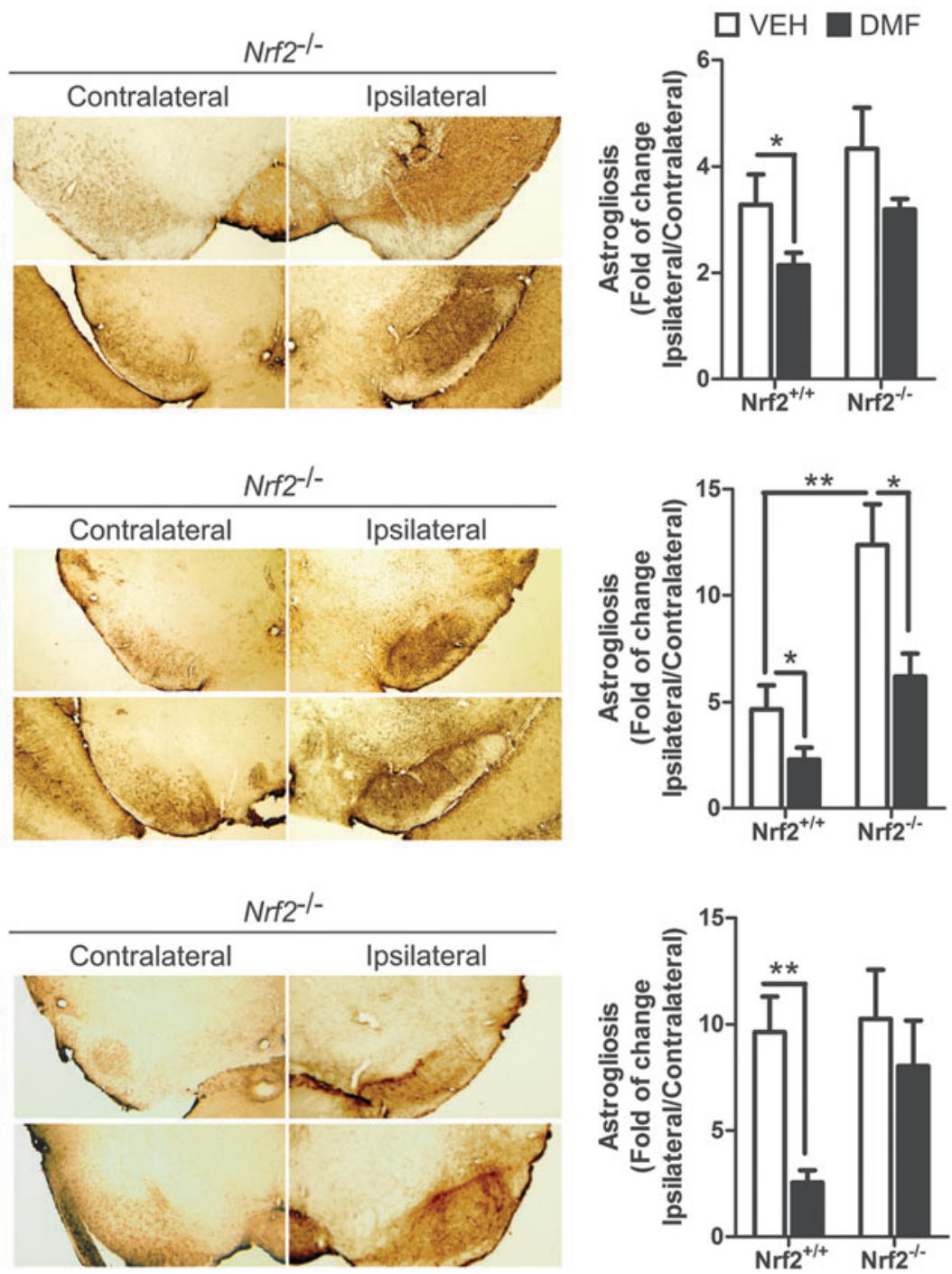

FIG. 4. DMF attenuates $\alpha$-SYN-induced astrogliosis. Photographs show immunohistochemistry for the astrocyte marker GFAP in $30 \mu$ m-thick sections of contralateral and ipsilateral sides of the VMB of $\mathrm{Nrf}_{2}{ }^{+/+}$and $\mathrm{Nrf}^{-/-}$mice after 1 week (A), 3 weeks (B), and 8 weeks (C) from injection with rAAV6- $\alpha-$ SYN and DMF treatment. Graphs indicate astrocyte number given as ratio between the ipsilateral and contralateral sides ( $n=4-6$ animals per group). Differences among groups were assessed by two-way ANOVA followed by Bonferroni's test. Asterisks denote significant differences ${ }^{*} p<0.05$ and ${ }^{* *} p<0.01$, comparing the indicated groups. To see this illustration in color, the reader is referred to the web version of this article at www.liebertpub.com/ars

shown). Moreover, $\mathrm{Nrf}^{-/-}$microglia showed impaired phagocytosis in comparison to wild-type microglia, as previously reported (45), and DMF increased the phagocytic activity of $\mathrm{Nrf}^{+/+}$but not in $\mathrm{Nrf}^{-/-}$microglia (Fig. 6B). To examine the anti-inflammatory effect of DMF against $\alpha$-SYN, BV2 cells were pretreated with this drug $(20 \mu M)$ and after $2 \mathrm{~h}$, the cells were shifted to normal medium or to medium supplemented with recombinant $\alpha$-SYN $(1 \mu M)$ and incubated for $6 \mathrm{~h}$. As shown in Figure $6 \mathrm{C}-\mathrm{E}, \alpha-\mathrm{SYN}$ induced mRNA and protein levels of the classical pro-inflammatory markers IL- $1 \beta$ and iNOS, and the pretreatment with DMF attenuated this effect. These results suggest that DMF reduces the ratio of microglial classical versus alternative phenotypes.

\section{Effect of DMF in autophagy}

As shown in Figure 7A, $\alpha$-SYN accumulated in neuron bodies and neurites in $\mathrm{Nrf2^{+/+ }}$ and $\mathrm{Nrf2^{-/- }}$ mice, suggesting a limiting capacity of the proteolytic clearance systems. Degradation of $\alpha$-SYN may be achieved through proteasome and autophagy pathways (76). The mRNA levels of several proteasome subunits did not change significantly after DMF treatment in MN9D, BV2, and IMA2.1 cells (Supplementary Fig. S5), although we have previously reported that NRF2deficiency is implicated in regulating proteasome activity (45). This discrepancy may be due to the slow turnover of proteasome subunits that cannot be substantially increased by DMF. For the purpose of this study, we focused on autophagy. We analyzed the levels of autophagosome cargo protein p62, because its expression is regulated by NRF2 $(32,41)$ and it has been reported to participate in autophagy of $\alpha$-SYN $(66,74)$. We also analyzed LC3, a protein specifically associated with autophagic vesicles whose lipidized levels (LC3II) correlate with autophagosome abundance.

In neuron-derived dopaminergic MN9D cells, DMF increased the levels of p62 with a maximum at $4 \mathrm{~h}$, which then 
A

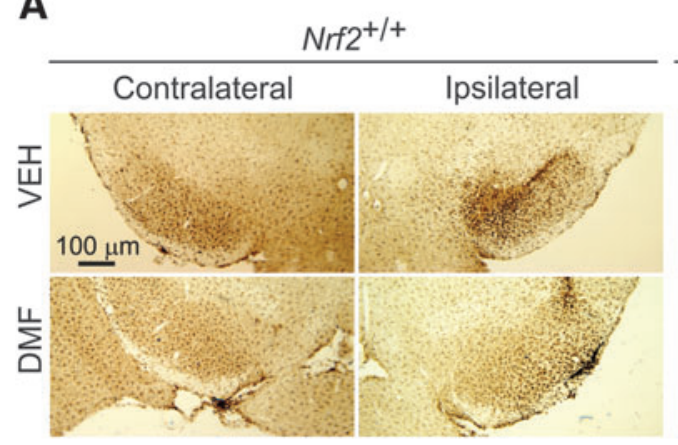

B

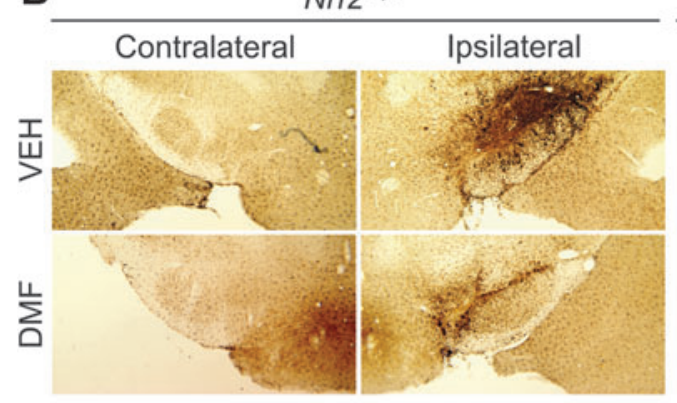

C

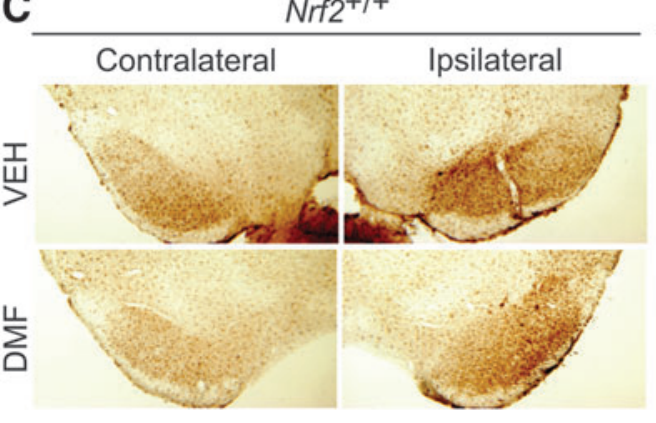

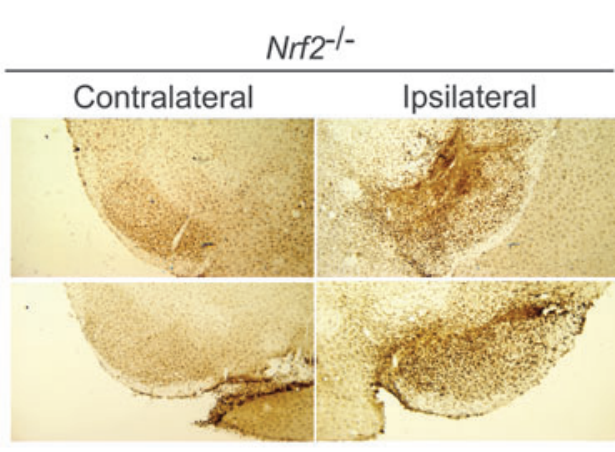
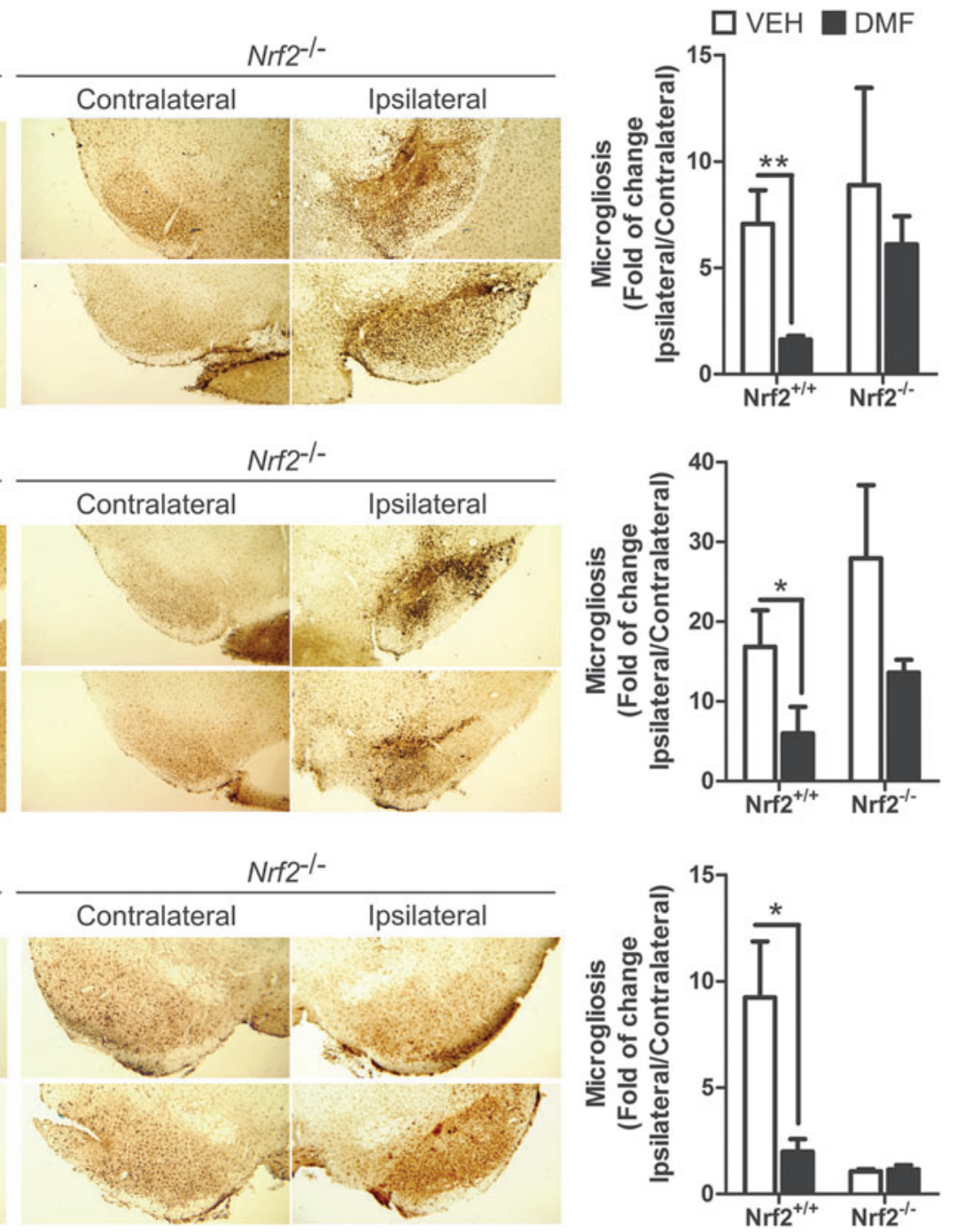

FIG. 5. DMF attenuates $\alpha$-SYN-induced microgliosis. Photographs show immunohistochemistry for the microglial marker IBA1 in $30 \mu \mathrm{m}$-thick sections of contralateral and ipsilateral sides of the VMB of $\mathrm{Nrf}^{+/+}$and $\mathrm{Nrf} 2^{-/-}$mice after 1 week (A), 3 weeks (B), and 8 weeks (C) from rAAV6- $\alpha-S Y N$ injection and DMF treatment. Graphs indicate microglial number given as ratio between the ipsilateral and contralateral sides ( $n=4-6$ animals per group). Differences among groups were assessed by two-way ANOVA followed by Bonferroni's test. Asterisks denote significant differences $* p<0.05$ and $* * p<0.01$, comparing the indicated groups. To see this illustration in color, the reader is referred to the web version of this article at www.liebertpub.com/ars

decreased even below basal levels by $24 \mathrm{~h}$ (Fig. 7B, C). LC3II remained stable during the first $4 \mathrm{~h}$ but decreased after 8 $24 \mathrm{~h}$. To further determine whether these changes might be due to a modification in the autophagic flux, we used the autophagy inhibitor bafilomycin A1 (Baf.A1). MN9D cells were serum-deprived for $16 \mathrm{~h}$, then pretreated with Baf.A1 (400 $\mathrm{n} M, 1 \mathrm{~h})$ before further addition of DMF or vehicle (20 $\mu M, 4 \mathrm{~h}$ ) (Fig. 7D). As expected, the blockage of autophagy flux by Baf.A1 led to the accumulation of p62 and LC3II. The combined Baf.A1/DMF treatment resulted in further accumulation of p62 but not of LC3. Moreover, immunocytochemical analysis of LC3 (Fig. 7E) showed the accumulation of autophagic vacuoles in the presence of Baf.A1 but DMF co-treated cells did not show a further increase. These results suggest that DMF favors autophagy by providing more cargo protein p62 but has a minor role in the autophagic flux since the levels of LC3-II (Fig. 7D) and LC3-positive vacuoles (Fig. 7E) were not significantly altered by this drug. Then, we analyzed these autophagy makers in microglia and astrocytes. In microglial BV2 cells, DMF induced a timedependent variation of the levels of p62 with a maximum at $8 \mathrm{~h}$ and a return to baseline by $24 \mathrm{~h}$ (Fig. 8A, B). LC3-II increased at $4 \mathrm{~h}$ but decreased even below baseline by $8 \mathrm{~h}$ (Fig. 8A, B). In murine IMA2.1 astrocytes, DMF induced a slight accumulation of p62, maximal at $4 \mathrm{~h}$, but contrary to BV2 cells, LC3-II accumulated gradually at least during the first $24 \mathrm{~h}$ of treatment (Fig. 8C, D). We further analyzed the autophagy flux in primary microglia submitted to Baf.A1 or DMF (Fig. 8E). Like in MN9D cells, the amount of LC3positive vacuoles was augmented after Baf.A1 treatment but was not significantly increased by DMF. Taken together, these results suggest that DMF modulates p62-dependent autophagy but different nerve cells may have slightly different responses. 
To analyze the effect of synucleinopathy in NRF2mediated autophagy, we performed double immunofluorescence of human $\alpha$-SYN versus LC3 or p62 in $30 \mu \mathrm{m}$-thick sections of VMB (Fig. 9A). LC3 localization did not clearly correlate with human $\alpha$-SYN staining but similar to the observations in MN9D cells, DMF decreased the overall level of LC3 in $\mathrm{Nrf}^{+/+}$mice. Regarding p62, we found $\alpha-\mathrm{SYN}$ expressing neurons with or without overall expression of $\mathrm{p} 62$ but in DMF-treated $\mathrm{Nrf}^{+/+}$mice, there was a tendency to find more cells co-expressing $\alpha-S Y N$ and p62 (Fig. 9B). Although
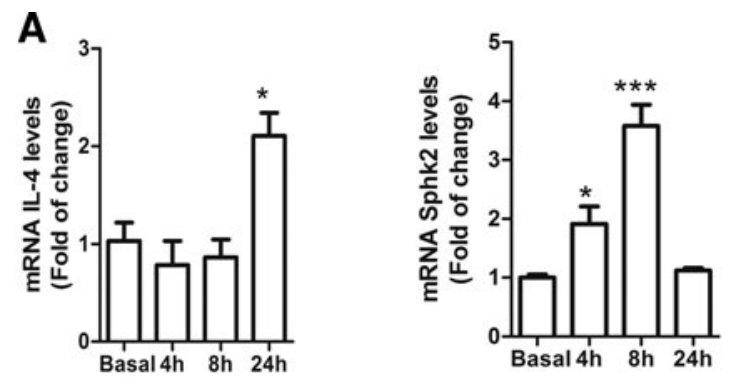

\section{B}
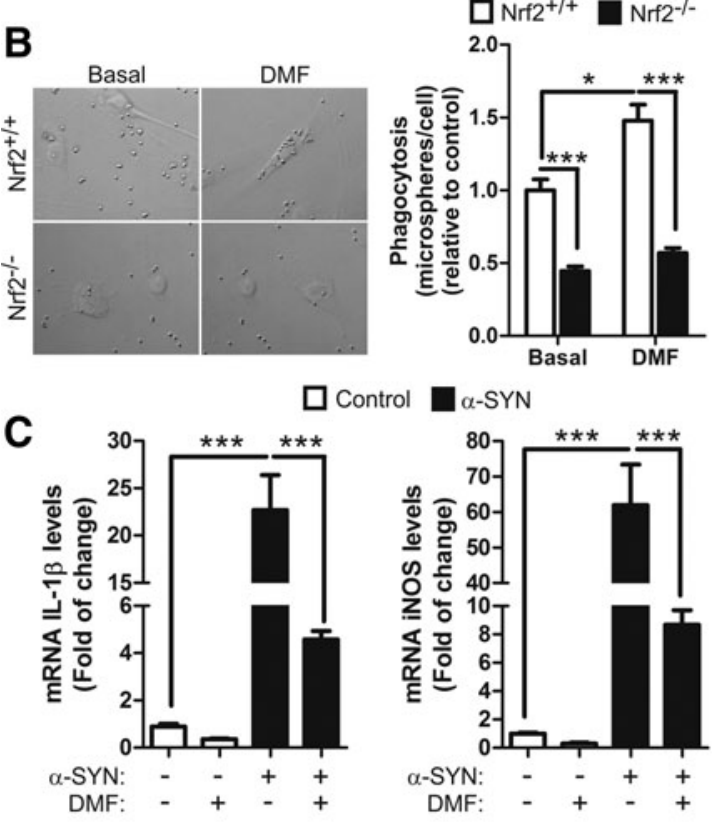

$\square$ Control

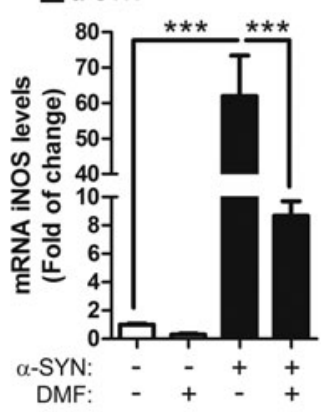

D
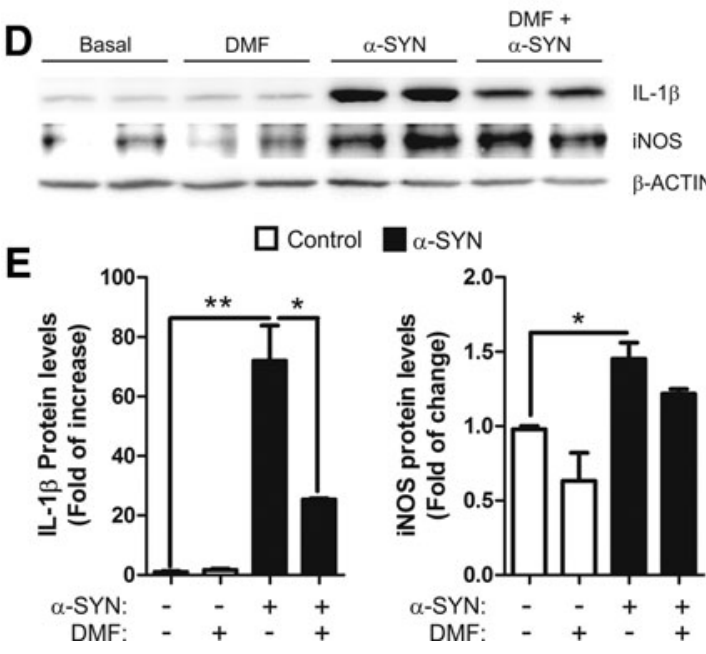

$\alpha-S Y N$

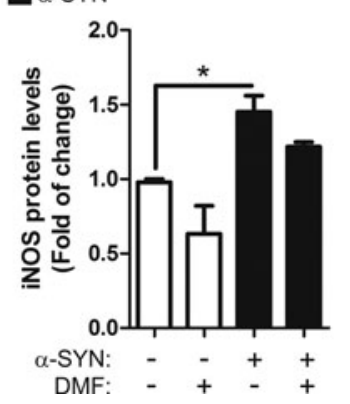

to our knowledge there are still no PD patients treated with DMF, we wanted to anticipate a possible correlation between NRF2 activity and this human synucleinopathy. Markers of NRF2 activation were analyzed in postmortem samples of asymptomatic subjects and PD patients. Due to the unspecific staining of available anti-NRF2 antibodies, we used NQO1 and p62 as two combined markers reflecting activation of the NRF2. Also, to circumvent the problem associated with different retrieval requirements for each antigen, we analyzed two adjacent $4 \mu \mathrm{m}$-thick sections that, in many cases, showed part of the same cell. As shown in Figure 9C, the SN pars compacta of two patients exhibited scattered dopaminergic neurons loaded with neuromelanin and $\alpha$-SYN. These neurons were positive for NQO1 staining not only in neuronal bodies but also in Lewy bodies. Similarly, p62 was found not only in the cytoplasm but also decorating the periphery of Lewy bodies of dopaminergic neurons. These results suggest that some dopaminergic neurons up-regulate the NRF2 response, possibly in an attempt to protect from $\alpha-\mathrm{SYN}$ toxicity and subsequent oxidative stress but, due to partial sequestration of NRF2-regulated products such as NQO1 and p62 in Lewy bodies, the physiological NRF2 response may be insufficient for mounting an optimal cellular defense and may need a pharmacological reinforcement.

\section{Discussion}

Several drugs have been used for proof-of-concept studies that strongly suggest that activation of NRF2 may provide a benefit against the Parkinsonian toxins 6-hydroxydopamine and 1-methyl-4-phenyl-1,2,3,6-tetrahydropyridine, which generate oxidative stress in the nigrostriatal track of rodents [for a review, see (37)]. From the point of view of clinical significance, these studies present two problems: (i) Most compounds tested lack biopharmaceutical pipelines that could proceed toward a clinical setting; (ii) "curing" oxidative stress-induced parkinsonism in rodents, while interesting and predictable as proof of concept, may have little impact in the much more complex pathology of human PD.

This study was aimed at determining whether pharmacological targeting of NRF2 might provide a disease-modifying therapy for the motor symptoms of PD by using a mouse model that replicates the main features of the human synucleinopathy. Our mouse model replicates the presence of $\alpha$ -

FIG. 6. DMF favors alternative over classic microglial phenotype. (A) qRT-PCR determination in BV2 cells of mRNA levels for alternative marker $I L-4$ (repair phenotype) and Sphk2 (immunomodulatory phenotype), normalized by $\beta$-actin. (B) effect of DMF on the phagocytic response of primary microglia to DMF $(20 \mu M, 2 \mathrm{~h})$. Phagocytic efficiency was calculated as number of microspheres per cell. (C) microglial BV2 cells were pretreated with DMF (20 $\mu M$, $2 \mathrm{~h}$ ), and then medium was changed to stimulate with $\alpha-S Y N$ $(1 \mu M, 6 \mathrm{~h})$. qRT-PCR determination of mRNA levels of pro-inflammatory cytokine $I L-1 \beta$ and inflammotoxic $i N O S$, normalized by $\beta$-actin. (D, E) BV2 cells were treated as mentioned earlier, and immunoblot analysis and densitometric quantification were performed as indicated. Two-way ANOVA followed by Bonferroni's test was used to assess differences among groups. Asterisks denote significant differences with $* p<0.05$, ** $p<0.01$, and $* * * p<0.001$ comparing the indicated groups. 
FIG. 7. Effect of DMF on autophagy of dopaminergic cells. (A) $\alpha$-SYN staining of nigral dopaminergic neurons. Arrowheads indicate $\alpha$-SYN accumulation in intracellular granules $(n=3-7$ animals per group). (B) Immunoblot analysis and densitometric quantification of autophagic markers p62 and LC3 in the dopaminergic MN9D cell line treated with $\mathrm{DMF}$ $(20 \mu M)$ for 4,8 , and $24 \mathrm{~h}$. (C) Immunoblot analysis and densitometric quantification of autophagic markers p62 and LC3, and NRF2-regulated HO1 in MN9D cells treated with DMF $(20 \mu M)$ for $24 \mathrm{~h}$. (D, E) MN9D cells were serumstarved for $16 \mathrm{~h}$ and pretreated with bafilomycin A1 (400 $\mathrm{n} M$, $1 \mathrm{~h})$ and then DMF $(20 \mu M)$ was added for $4 \mathrm{~h}$. (D) Immunoblot analysis and densitometric quantification of autophagic markers p62 and LC3. (E) Immunohistochemistry for LC3 and quantification. Asterisks denote significant differences with $* p<0.05, * * p<0.01$, and $* * *$ $p<0.001$ comparing the indicated groups with the basal condition according to a oneway ANOVA followed by Newman-Keuls post-test. To see this illustration in color, the reader is referred to the web version of this article at www .liebertpub.com/ars
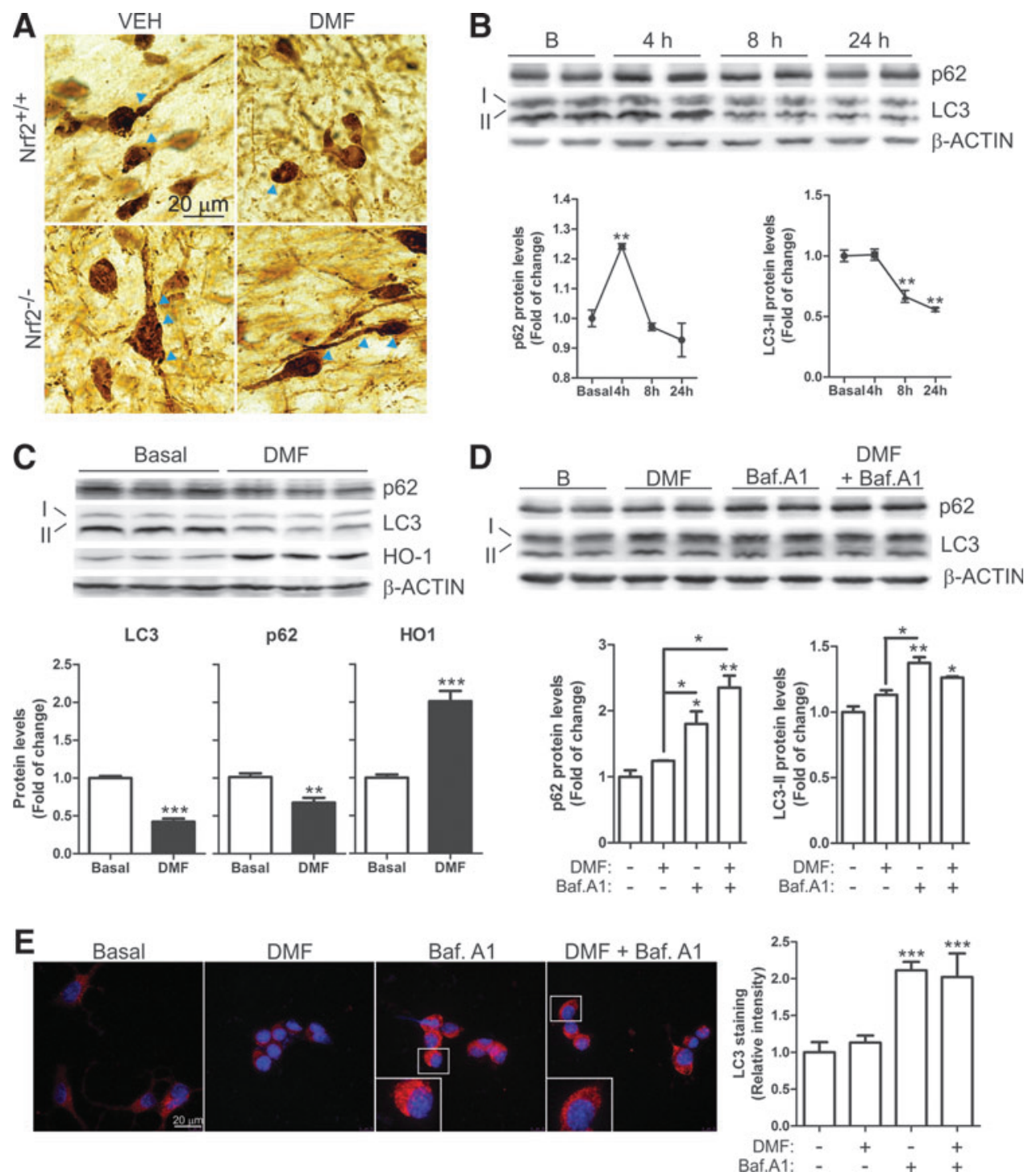

SYN containing intracellular aggregates and dystrophic neurites, leads to a robust and selective loss of nigral dopaminergic neurons, and correlates with strong astrogliosis and microgliosis. It is generally believed that protofibrils made of conformationally altered $\alpha$-SYN lead to neuronal death in both idiopathic and, at least, some familiar cases of PD, where the $\alpha$-SYN coding gene has suffered duplications or triplications. The process of $\alpha$-SYN aggregation into Lewy bodies has been used to stage PD progression and is discussed in detail in (9). Considering the level of $\alpha$-SYN aggregation into dystrophic Lewy dendrites and aggregates, this mouse model seems to replicate the early stages of PD where abnormal $\alpha$-SYN deposition occurs and becomes the driving force in PD pathogenesis (64). A remaining limitation of this model is that it only replicates histological and motor symptoms of PD that are associated with nigrostriatal pathology. However, because DMF is administered systemically and NRF2 appears to provide multiple layers of tissue protection, including oxidative, inflammatory, and proteotoxic stress, it is tempting to speculate that systemic activation of NRF2 will also provide a relief of nonmotor symptoms such as constipation, sleep disturbance, depres- sion, or dementia, among others. Thus, oxidative stress during inflammation causes persistent dysfunction of colonic smooth muscle that leads to motility dysfunction, and it has been reported that the NRF2 activator sulforaphane can attenuate this pathological mark in a model of inflammatory bowel disease (20). Regarding sleep disturbance, NRF2 is regulated by an E-box-mediated circadian rhythm that combats oxidative/fibrotic lung damage, and timed administration of sulforaphane significantly blocks this effect in a murine model of bleomycin-induced lung fibrosis (52). Another co-morbidity associated with PD is depression, and it has been reported that NRF2 activation prevents depressivelike behavior in mice $(23,47)$. Finally, dementia is becoming one of the most difficult symptoms to palliate in late PD. However, although this issue has not yet been addressed in a preclinical model of $\mathrm{PD}$, there is strong evidence indicating that the NRF2 might protect the cholinergic system in Alzheimer's disease mouse models $(40,62)$.

In preliminary experiments, we searched for the most suitable dosing of DMF that might provide a modest activation of the NRF2 signature in the brain, yet lack significant toxicity and stay within clinically relevant values. In 

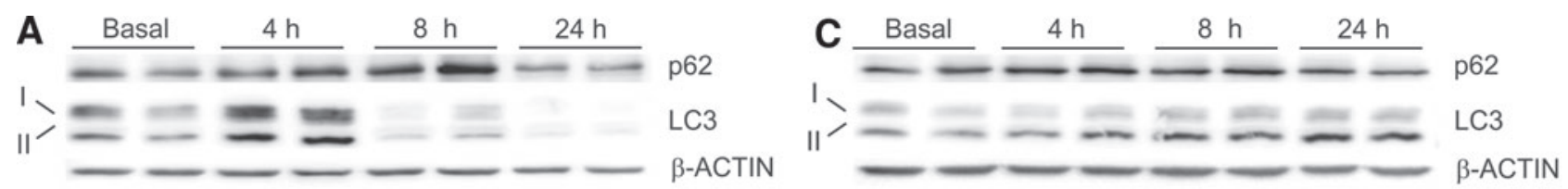

B
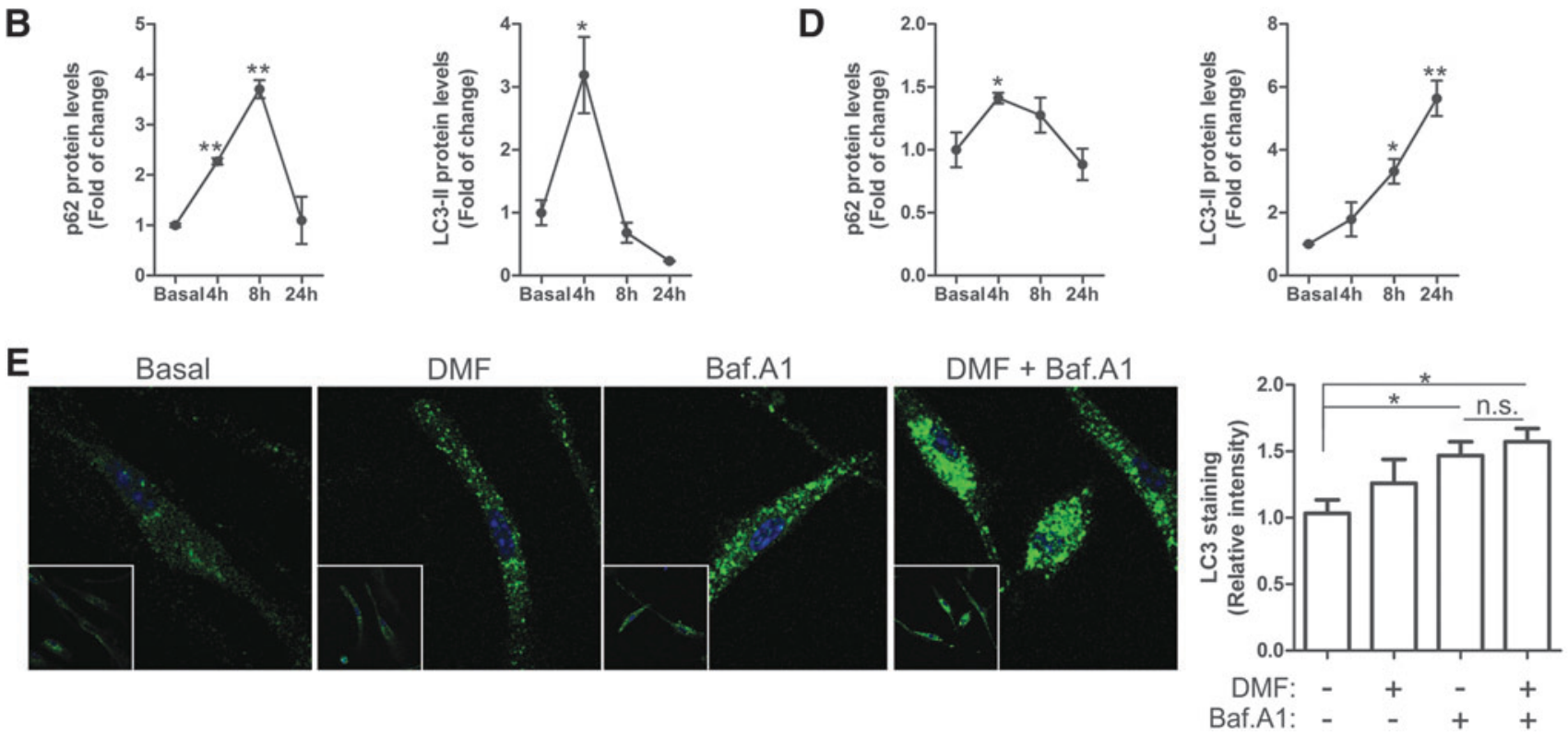

FIG. 8. Effect of DMF on glial autophagy. Immunoblot analysis and densitometric quantification of autophagic markers p62 and LC3 in microglial BV2 cells (A, B) and astrocytic IMA 2.1 cells $(\mathbf{C}, \mathbf{D})$. Cell lines were treated with DMF $(20 \mu M)$ for 4, 8, and $24 \mathrm{~h}$. (E) Immunohistochemistry for LC3 and quantification in primary microglial cells, which were serum-starved for $16 \mathrm{~h}$ and then pretreated with bafilomycin A1 $(400 \mathrm{n} M, 1 \mathrm{~h})$, and then DMF $(20 \mu M)$ was added for $4 \mathrm{~h}$. Asterisks denote significant differences $* p<0.05$, ** $p<0.01$ comparing the indicated groups with the basal condition according to a one-way ANOVA followed by Newman-Keuls post-test. To see this illustration in color, the reader is referred to the web version of this article at www .liebertpub.com/ars

agreement with former studies in experimental autoimmune encephalomyelitis (10), the $100 \mathrm{mg} / \mathrm{kg}$ dose elicited a modest but persistent activation of the NRF2 signature. In humans, the usual dose is $480 \mathrm{mg}$ but the pharmacokinetics between rodents and humans is different. Thus, in a plot of DMF concentration in plasma over time $(24 \mathrm{~h})$, we found that the area under the curve in rodents submitted to $100 \mathrm{mg} / \mathrm{kg}$ was just two-fold higher than in humans submitted to $480 \mathrm{mg}$ DMF [data not shown (59)]. . Moreover, at the $100 \mathrm{mg} / \mathrm{kg}$ dose, we did not observe in mice any significant evidence of toxicity, such as weight loss, hair loss, or other gross alterations. In humans, toxicity of DMF does not appear to be an important concern since some patients with multiple sclerosis have been taking this drug for more than 5 years with little or no evidence of adverse effects.

The elevated body swing test used here to evaluate motor performance was highly predictive of the degree of nigrostriatal injury as previously reported $(3,8)$. It provided the first evidence of a beneficial effect of DMF that was further confirmed by preservation at 1,3 , and 8 weeks from surgery of $\mathrm{TH}^{+}$neuron bodies in the SN and fibers in the STR in $N r f 2^{+/+}$but not $N r f 2^{-/-}$mice. Other motor tests used, such as the cylinder, apomorphine, and open-field test, were not sensitive enough to predict nigrostriatal damage (data not shown). The denervation of the STR, as a result of retrograde transport of $\alpha$-SYN from the SN, was not as dramatic as the loss of $\mathrm{TH}^{+}$neuronal bodies at the $\mathrm{SN}$, which is consistent with the existence of compensatory mechanisms that favor sprouting of remaining dopaminergic fibers $(34,45,55)$. But most importantly, the continuous administration of DMF to the $\mathrm{Nrf2}^{+/+}$mice strongly attenuated loss of both dopaminergic neuron bodies at the SN and fibers at the STR. This protection was not found in the DMF-treated $\mathrm{Nrf}^{-/-}$mice, further indicating that DMF is targeting NRF2 for this protective effect. In fact, only the DMF-treated $\mathrm{Nrf}^{+/+}$mice could stand the expression of human $\alpha-\mathrm{SYN}$ after 1,3 , and 8 weeks. It is interesting that DMF also induced a mild reduction of astrogliosis and microgliosis in the $\mathrm{Nrf}^{-/-}$mice. This is consistent with the reported inhibitory effect of this drug on NF- $\kappa \mathrm{B}$ activity in an NRF2-independent manner (25).

The analysis of the nigrostriatal lesion after 1 week from surgery was very informative about early events leading to synucleinopathy. Several reports suggest that NRF2 upregulates the expression of proteasome genes and probably autophagy genes $(38,43)$, and, thus, the $N r f 2^{-1-}$ mice would be expected to be more sensitive to $\alpha$-SYN toxicity. In this context, it has been described that p62 interacts directly with KEAP1, demonstrating that p62-mediated NRF2 upregulation is KEAP1 dependent (46) and NRF2 up-regulates the expression of p62 (32). Consistently, DMF induced p62 protein levels in cultured neural cells but the DMF modulation of autophagy may be more complex than NRF2 targeting, as it has been suggested for sulforaphane, a well-established 

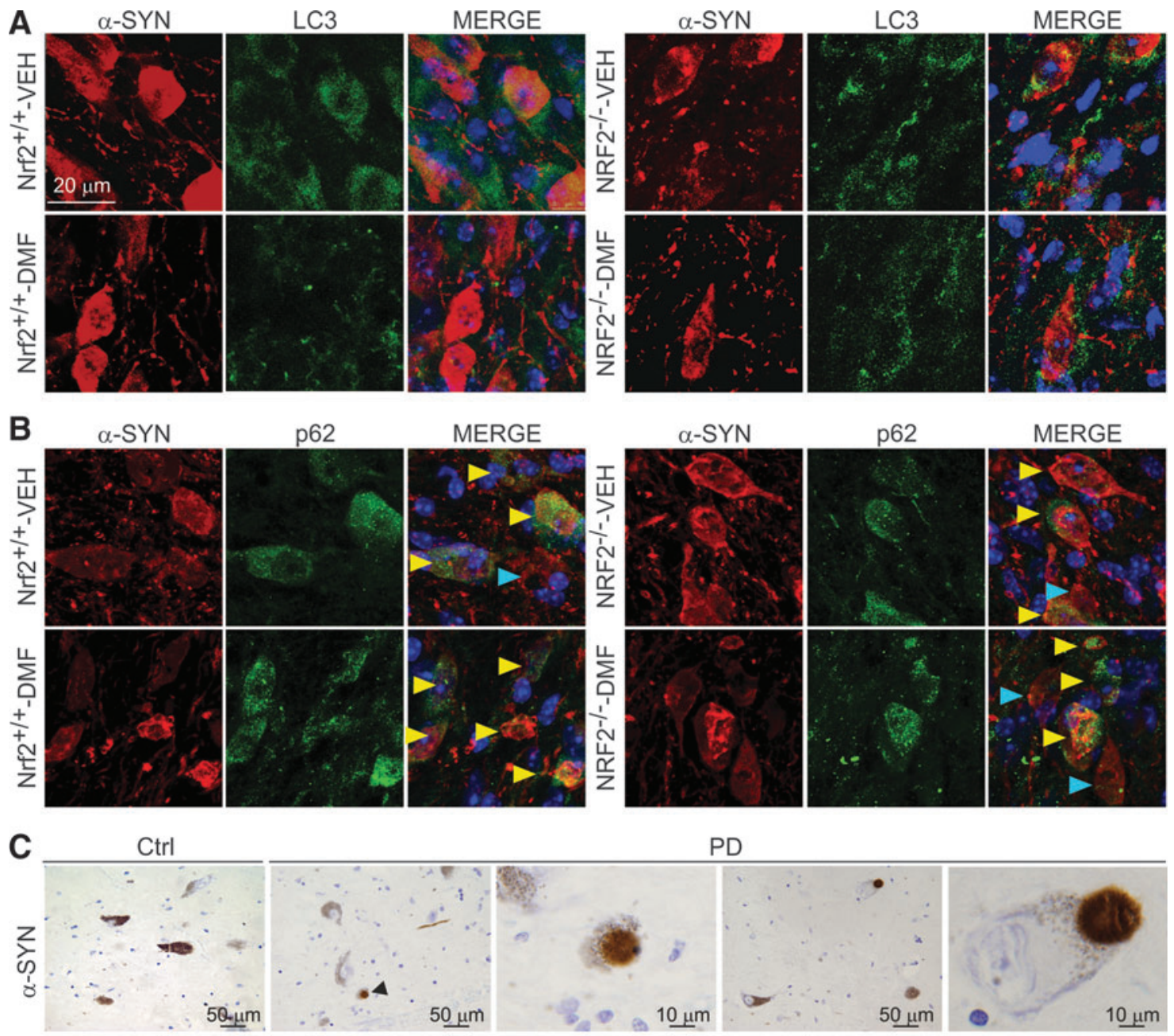

PD
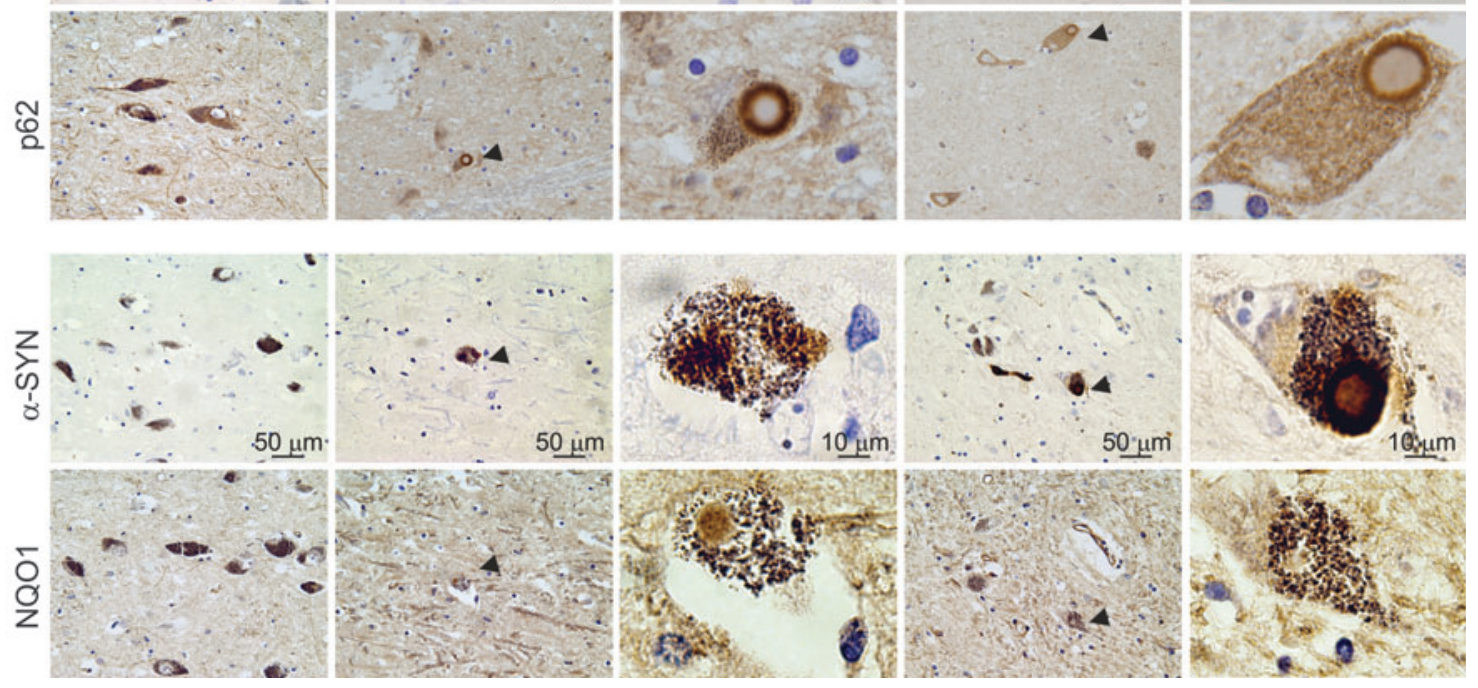

FIG. 9. Markers of autophagy in human $\alpha$-SYN-expressing mice and human PD brain samples. (A) immunofluorescence for LC3 (green) and $\alpha$-SYN (red) of $30 \mu$ m-thick sections of SN from $N r f 2^{+/+}$and $N r f 2^{-/-}$mice after 1 week from injection with rAAV6- $\alpha-S Y N$ and DMF treatment. (B) immunofluorescence for p62 (green) and $\alpha$-SYN (red) of $30 \mu$ mthick sections of SN from $N r f 2^{+/+}$and $\mathrm{Nrf}^{-/-}$mice after 1 week from injection of rAAV6- $\alpha-\mathrm{SYN}$ and DMF treatment. Yellow arrowheads point to neurons co-expressing p62 and human $\alpha-S Y N$; blue arrowheads point to neurons expressing preferentially human $\alpha$-SYN. (C) Localization of Nrf2-regulated gene products p62 and NQO1 in Lewy bodies. The immunohistochemistries correspond to two adjacent $4-\mu \mathrm{m}$-thick sections from a control asymptomatic subject and a PD patient. Arrowheads indicate $\alpha$-SYN-positive Lewy bodies surrounded by p62 or NQO1 protein. Upper panels, immunohistochemistry of $\alpha$-SYN and p62. Lower panels, immunohistochemistry of $\alpha-\mathrm{SYN}$ and NQO1. To see this illustration in color, the reader is referred to the web version of this article at www.liebertpub.com/ars 
NRF2 activator, that also promotes autophagy by regulating ERK (36) or AMPK (79). In any case, these observations collectively indicate that DMF regulates autophagy, at least in part, by regulating the NRF2/p62 axis.

DMF led to changes in the levels of the lipidated LC3-II form, although with different kinetics in the three nerve cells analyzed, suggesting a different mechanism of regulation. A puzzling result was that the level of LC-3II and the number of LC-3+ autophagy vesicles was not further increased after treatment with the autophagy flux blocker Baf.A1 in either MN9D cells or microglia. The combination of LC-3 and Baf.A1 has been traditionally used as a method to monitor autophagy flux, and, therefore, it was surprising to find that DMF did not clearly change this flux. Then, the DMFinduced changes in LC-3II levels in the absence of Baf.A1 must be attributed to variations in the composition of autophagosomes rather than to a net change in the autophagy flux. It remains to be determined whether LC3 is modulated by NRF2. The messenger RNA levels of LC-3 are similar in $\mathrm{Nrf2}^{+/+}$and $\mathrm{Nrf2}^{-/-}$cortical neurons (data not shown) and the kinetics of induction of p62 and LC3 by DMF is different (Figs. 7 and 8), therefore suggesting that LC3 is not regulated directly by DMF or NRF2. Taken together, we suggest that DMF regulates the NRF2/p62 axis to provide more cargos such as $\alpha$-SYN to the autophagosome and has a global but still not fully defined effect on autophagy, as reflected by changes in LC-3II levels.

We and others have reported the relevance of NRF2 in modulation of acute and chronic neuroinflammation $(29,33$, 56), and the experimental and clinical evidence suggests that DMF has a very relevant role in targeting inflammation (1, 75). DMF modulated the microglial response to $\alpha-S Y N$, shifting from a more pro-inflammatory phenotype (IL-1 and iNOS) toward a more alterative phenotype (IL-4 and SPHK2) in vitro, and probably during the early stages of damage to the brain parenchyma, because microgliosis was attenuated at 1 and 3 weeks. The fact that we could not see a significant microgliosis at 8 weeks suggests that the initial neuron damage elicited by $\alpha$-SYN overexpression led to microgliosis that remitted only when most neurons had died. It is interesting to note that DMF induced microglial phagocytosis in an NRF2-dependent manner. This intriguing observation has also been reported for the NRF2 activator sulforaphane (65) and in our previous work (45). In peripheral macrophages, the phagocytosis-stimulating activity of some pro-resolving lipid mediators of inflammation was significantly impaired in $\mathrm{Nrf}^{-1-}$ macrophages, which already had a weakened basal phagocytic function (53). Mechanistically, to our knowledge, there is not yet a conclusive explanation, but we have reported that the expression of some receptors involved in phagocytosis (TAM receptors) is slightly decreased in NRF2defficient microglia $(44,45)$. Other evidence suggests that NRF2 modulates the expression of scavenger receptors such as MARCO (macrophage receptor with collagenous structure) (7) and CD36 (30).

Contrary to microglia, astrogliosis was also observed at 8 weeks. This was most likely due to an accumulative effect, since astrocytes will fill the empty spaces left by dead neurons and will remain there as a mark of the neuronal lesion. The protective effect of DMF was very obvious when we analyzed the degree of astrogliosis in mice injected with rAAV-6- $\alpha-S Y N$. Thus, in the STR of vehicle-treated $N r f 2^{+/+}$ mice, we observed abundant astrocytes that were largely decreased in the DMF-treated counterparts.

The global results of this study are presented in an idealized graph in Supplementary Figure S6. It is predicted that overexpression of human $\alpha-S Y N$ leads to a rapid, less than 3week, intoxication of nigrostriatal dopaminergic neurons of $\mathrm{Nrf2}^{+/+}$and $\mathrm{Nrf2}^{-/-}$mice. This injury is slightly higher in the $N r f 2^{-/-}$mice (Fig. 3). In parallel to neuron intoxication, we find microglial activation that will elicit an inflammatory response and remove neuronal debris but will cease once $\alpha$ SYN intoxicated neurons have disappeared. Microglial activation will be lower in DMF-treated $\mathrm{Nrf}^{+/+}$mice, because they exhibit less neuron damage (Figs. 5 and 3, respectively). Astrocytes are activated in parallel to neuronal intoxication but contrary to the microglia, they remain detectable after the phase of injury, creating a scar in the damaged tissue (Fig. 4). The astroglial scar is smaller in the DMF-treated mice, because the death of dopaminergic neurons was attenuated by this drug. Further work may be required for obtaining a fine analysis of the participation of DMF and NRF2 in prevention of proteinopathy, but from a clinical perspective, DMF is now ready for clinical analysis for the treatment of $\mathrm{PD}$.

\section{Materials and Methods}

\section{Cell culture}

MN9D is an immortalized dopaminergic neuronal cell line derived from mouse mesencephalon (19). IMA 2.1 astroglial cells were provided by Dr. Stefan Schildknecht (University of Konstanz, Konstanz, Germany). MN9D and IMA2.1 were grown in Dulbecco's modified Eagle's medium (DMEM) supplemented with $10 \%$ fetal bovine serum and $80 \mu \mathrm{g} / \mathrm{ml}$ gentamicin. BV2 microglial cells were cultured in RPMI 1640 medium supplemented with $10 \%$ fetal calf serum and $80 \mu \mathrm{g} / \mathrm{ml}$ gentamicin. Primary microglia were prepared from neonatal (P0-P2) mouse cortex from $N r f 2^{+/+}$and $\mathrm{Nrf}^{-/-}$and were isolated and grown as described in (45). The medium was changed to serum-free DMEM without antibiotics at $16 \mathrm{~h}$ before treatment.

\section{Immunoblotting}

Whole brain lysates were prepared as previously described (57). Immunoblots were performed as described in (15). The primary antibodies used are described in Supplementary Table S1.

\section{Analysis of $m R N A$ levels by quantitative real-time polymerase chain reaction}

Total RNA extraction, reverse transcription, and quantitative polymerase chain reaction (PCR) were done as detailed elsewhere (44). Primer sequences are shown in Supplementary Table S2. Data analysis was based on the $\Delta \Delta$ CT method with normalization of the raw data to housekeeping genes (Applied Biosystems). All PCRs were performed in triplicate.

\section{Phagocytosis assay}

About 150,000 cells of primary microglia from $\mathrm{Nrf}^{+/+}$and $N r f 2^{-1-}$ mice were plated on coverslips for $16 \mathrm{~h}$. Then, the medium was replaced with serum-free DMEM without 
antibiotics for $24 \mathrm{~h}$ before adding 150 microspheres per cell (FluoSpheres polystyrene microspheres; Invitrogen) and DMF $(20 \mu M)$ and incubating for $2 \mathrm{~h}$. Then, the cells were washed with PBS, fixed with $4 \%$ paraformaldehyde, and stained with 4',6-diamidino-2-phenylindole (DAPI) (Molecular Probes). The images were captured by using a $90 \mathrm{i} \mathrm{Ni}-$ kon microscope (Nikon) with a $40 \times$ objective.

\section{Immunocytochemistry}

Primary microglia from $\mathrm{Nrf} 2^{+/+}$and MN9D cells were seeded in 24-well plates. After $24 \mathrm{~h}$, the cells were shifted to serum-free DMEM without antibiotics. After treatments, the cells were washed with cold PBS and fixed with $4 \%$ paraformaldehyde for $10 \mathrm{~min}$. The cells were permeabilized with $0.25 \%$ Nonidet NP-40 (Sigma-Aldrich) for $10 \mathrm{~min}$ and incubated with primary antibodies for $1.5 \mathrm{~h}$ at $37^{\circ} \mathrm{C}$ in a humidified box. Secondary antibodies were incubated for $45 \mathrm{~min}$ at $37^{\circ} \mathrm{C}$ under the same conditions. Cells were counterstained with DAPI. Fluorescent images were captured by using appropriate filters in a Leica DMIRE2TCS SP2 confocal microscope (Leica).

\section{Animals and treatments}

Colonies of $\mathrm{Nrf}^{-/-}$mice and $\mathrm{Nrf2^{+/+ }}$ littermates were established from funders kindly provided by Prof. Masayuki Yamamoto (Tohoku University Graduate School of Medicine, Sendai, Japan) (31). Each experimental group comprised 5-8 animals. An adeno-associated pseudotype 6 (rAAV6) viral vector was used to express human $\alpha$-SYN under the neuron-specific human Synapsin 1 promoter (42). Vector batches yielded $3.5 \times 10^{8} \mathrm{TU} / \mu \mathrm{l}$ titers, and stock preparations were diluted two-fold for in vivo injections. Surgical procedures and a unilateral intracerebral injection of viral particles into the right hemisphere were performed as described (45) with several modifications. Briefly, animals received a single $2 \mu \mathrm{l}$ injection into the right $\mathrm{SN}$ at the following coordinates: $-2.8 \mathrm{~mm}$ posterior and $-1.4 \mathrm{~mm}$ lateral to bregma, and $-4.5 \mathrm{~mm}$ ventral relative to dura, calculated according to the mouse atlas of (51). All experiments were performed by certified researchers according to regional, national, and European regulations concerning animal welfare and animal experimentation, and they were authorized by the Ethics Committee for Research of the Autonomous University of Madrid. DMF $(100 \mathrm{mg} / \mathrm{kg}$ or $300 \mathrm{mg} / \mathrm{kg}$; Biogen) was suspended in $0.8 \%$ methocel and given by oral gavage. We did not detect significant weight loss, hair loss, or other gross alterations in the DMF-treated mice either in the 1 - and 3-week administration every day or in the 8-week administration every 2 days.

\section{Behavioral test}

The elevated body swing test is a simple and easy behavioral test that only requires handling the animal by its tail and recording the direction of swings made by the animal for a certain period $(3,8)$. Briefly, the animal was held in the vertical axis and a swing was recorded whenever the animal moved its head out of the vertical axis to either side. Before attempting another swing, the animal must return to the vertical position for the next swing to be counted. Each experimental group comprised 5-8 animals.

\section{Immunohistochemistry in mouse and human tissues}

Immunohistochemistry in mice was performed on $30 \mu \mathrm{m}$ thick coronal brain sections with a standard avidin-biotin immunohistochemical protocol (45). Primary antibodies are described in Supplementary Table S1. Human tissues were obtained from two controls (age 78 and 88 years) and three PD patients (aged 62, 65, and 84 years) within a $12 \mathrm{~h}$ postmortem interval, according to standard procedures of Banco de Tejidos de la Fundación CIEN. The control subjects had no background of neuropsychiatric disease, and a full neuropathological examination on paraffin-embedded tissue excluded relevant brain pathology. In PD patients, clinical diagnosis was confirmed by hematoxylin and eosin and $\alpha-S Y N$ staining on paraffin-embedded tissue sections. PD patients were categorized as Braak stage 6 for Lewy body pathology (9). Immunohistochemistry in human SN was done on $4 \mu$ thick paraffin-embedded samples. Primary antibodies were incubated with Dako REAL antibody diluents. After washing, the sections were incubated with the secondary biotinylated antiserum (Vector) and then with the ABC kit system, and they were developed by using 3,3'-diaminobenzidine.

\section{Stereological analysis}

Cell counts were performed every four sections (30 $\mu \mathrm{m}$ thick) through the SN by using Stereo Investigator Software (MicroBrightfield) that was attached to an E800 Nikon microscope (Nikon). SN, excluding ventral tegmental area, was delineated in low magnification $(5 \times$ objective $)$, and a point grid was overlaid onto each section. Cell counting was performed as previously described by (21). The error coefficient attributable to the sampling was calculated according to Gundersen and Jensen (26), and values $\leq 0.10$ were accepted.

\section{Determination of monoamines and their metabolites}

Hemi-brains were frozen on dry ice until use. DA and its metabolite, DOPAC, were measured by HPLC with an ESA coulochem detector. Briefly, the tissue was sonicated in 6 vol. (weight/volume) of $0.4 \mathrm{~N}$ perchloric acid (PCA) with $0.5 \mathrm{mM}$ $\mathrm{Na}_{2} \mathrm{~S}_{2} \mathrm{O}_{5}$ and $2 \%$ EDTA and then centrifuged at 10,000 $g$ at $4^{\circ} \mathrm{C}$ for $20 \mathrm{~min}$. Monoamine levels were determined from $20 \mu \mathrm{l}$ of the resulting supernatant. The chromatographic conditions were as follows: A column (Nucleosil 5C18); the mobile phase, a citrate/acetate buffer $0.1 \mathrm{M}$, pH 3.9 with $10 \%$ methanol, $1 \mathrm{~m} M$ EDTA, and $1.2 \mathrm{~m} M$ heptane sulfonic acid; and the detector voltage conditions: D1 (+0.05), D2 (-0.39), and the guard cell $(+0.40)$ have been previously described (48).

\section{Immunofluorescence on mouse tissues}

The protocol was previously described (55). Primary antibodies are described in Supplementary Table S1. Secondary antibodies were as follows: Alexa Fluor 546 goat anti-mouse, Alexa 546 goat anti-rabbit, and Alexa Fluor 488 goat antimouse (1:500; Life technologies). Control sections were treated by following identical protocols but omitting the primary antibody.

\section{Statistical analyses}

Data are presented as mean \pm SEM. To determine the statistical test to be used, we employed GraphPad Instat 3, which 
includes the analysis of the data to normal distribution via Kolmogorov-Smirnov test. In addition, statistical assessments of differences between groups were analyzed (GraphPad Prism 5) by unpaired Student's $t$-tests when normal distribution and equal variances were fulfilled, or by the nonparametric Mann-Whitney test. One- and two-way ANOVA with post hoc Newman-Keuls test or Bonferroni's test were used, as appropriate.

\section{Acknowledgments}

This work was supported by grants from Biogen, SAF2013143271-R and "Fundación Salud 2000." ILB was recipient of a Ramón y Cajal contract (MICINN-RYC). The authors thank Johanna Troya-Balseca for her technical support.

\section{Author Disclosure Statement}

At the time this work was conducted, R.S. was an employee of and held stock/stock options in Biogen. All other authors declare no competing interests.

\section{References}

1. Albrecht P, Bouchachia I, Goebels N, Henke N, Hofstetter HH, Issberner A, Kovacs Z, Lewerenz J, Lisak D, Maher P, Mausberg AK, Quasthoff K, Zimmermann C, Hartung HP, and Methner A. Effects of dimethyl fumarate on neuroprotection and immunomodulation. J Neuroinflammation 9: 163, 2012.

2. Altmeyer PJ, Matthes U, Pawlak F, Hoffmann K, Frosch PJ, Ruppert P, Wassilew SW, Horn T, Kreysel HW, Lutz G, et al. Antipsoriatic effect of fumaric acid derivatives. Results of a multicenter double-blind study in 100 patients. $J$ Am Acad Dermatol 30: 977-981, 1994.

3. Bentea E, Van der Perren A, Van Liefferinge J, El Arfani A, Albertini G, Demuyser T, Merckx E, Michotte Y, Smolders I, Baekelandt V, and Massie A. Nigral proteasome inhibition in mice leads to motor and non-motor deficits and increased expression of Ser129 phosphorylated alpha-synuclein. Front Behav Neurosci 9: 68, 2015.

4. Beraud D, Hathaway HA, Trecki J, Chasovskikh S, Johnson DA, Johnson JA, Federoff HJ, Shimoji M, Mhyre TR, and Maguire-Zeiss KA. Microglial activation and antioxidant responses induced by the Parkinson's disease protein alpha-synuclein. J Neuroimmune Pharmacol 8: 94-117, 2013.

5. Blesa J, Phani S, Jackson-Lewis V, and Przedborski S. Classic and new animal models of Parkinson's disease. $J$ Biomed Biotechnol 2012: 845618, 2012.

6. Bomprezzi R. Dimethyl fumarate in the treatment of relapsing-remitting multiple sclerosis: an overview. Ther Adv Neurol Disord 8: 20-30, 2015.

7. Bonilla DL, Bhattacharya A, Sha Y, Xu Y, Xiang Q, Kan A, Jagannath C, Komatsu M, and Eissa NT. Autophagy regulates phagocytosis by modulating the expression of scavenger receptors. Immunity 39: 537-547, 2013.

8. Borlongan $\mathrm{CV}$ and Sanberg PR. Elevated body swing test: a new behavioral parameter for rats with 6hydroxydopamine-induced hemiparkinsonism. J Neurosci 15: 5372-5378, 1995.

9. Braak H, Del Tredici K, Rub U, de Vos RA, Jansen Steur EN, and Braak E. Staging of brain pathology related to sporadic Parkinson's disease. Neurobiol Aging 24: 197211, 2003.
10. Brennan M, Allaire N, Huss D, Cullen P, Thai A, Szak S, et al. Dimethyl fumarate and monomethyl fumarate are distinguished by non-overlapping pharmacodynamic effects in vivo (P1.206). Neurology 82(10 Suppl): P1.206., 2014.

11. Brennan MS, Matos MF, Li B, Hronowski X, Gao B, Juhasz $\mathrm{P}$, Rhodes KJ, and Scannevin RH. Dimethyl fumarate and monoethyl fumarate exhibit differential effects on KEAP1, NRF2 activation, and glutathione depletion in vitro. PLoS One 10: e0120254, 2015.

12. Burton NC, Kensler TW, and Guilarte TR. In vivo modulation of the Parkinsonian phenotype by Nrf2. Neurotoxicology 27: 1094-1100, 2006.

13. Castellani R, Smith MA, Richey PL, and Perry G. Glycoxidation and oxidative stress in Parkinson disease and diffuse Lewy body disease. Brain Res 737: 195-200, 1996.

14. Connolly BS and Lang AE. Pharmacological treatment of Parkinson disease: a review. JAMA 311: 1670-1683, 2014.

15. Cuadrado A, Martin-Moldes Z, Ye J, and Lastres-Becker I. Transcription factors NRF2 and NF-kappaB are coordinated effectors of the Rho family, GTP-binding protein RAC1 during inflammation. J Biol Chem 289: 1524415258, 2014.

16. Cuadrado A, Moreno-Murciano P, and Pedraza-Chaverri J. The transcription factor Nrf2 as a new therapeutic target in Parkinson's disease. Expert Opin Ther Targets 13: 319329, 2009.

17. Chen PC, Vargas MR, Pani AK, Smeyne RJ, Johnson DA, Kan YW, and Johnson JA. Nrf2-mediated neuroprotection in the MPTP mouse model of Parkinson's disease: critical role for the astrocyte. Proc Natl Acad Sci U S A 106: 29332938, 2009.

18. Chhor V, Le Charpentier T, Lebon S, Ore MV, Celador IL, Josserand J, Degos V, Jacotot E, Hagberg H, Savman K, Mallard C, Gressens P, and Fleiss B. Characterization of phenotype markers and neuronotoxic potential of polarised primary microglia in vitro. Brain Behav Immun 32: 70-85, 2013.

19. Choi HK, Won L, Roback JD, Wainer BH, and Heller A. Specific modulation of dopamine expression in neuronal hybrid cells by primary cells from different brain regions. Proc Natl Acad Sci U S A 89: 8943-8947, 1992.

20. Choi K, Chen J, Mitra S, and Sarna SK. Impaired integrity of DNA after recovery from inflammation causes persistent dysfunction of colonic smooth muscle. Gastroenterology 141: 1293-1301, 1301 e1-e3, 2011.

21. Decressac M, Ulusoy A, Mattsson B, Georgievska B, Romero-Ramos M, Kirik D, and Bjorklund A. GDNF fails to exert neuroprotection in a rat $\{$ alpha $\}$-synuclein model of Parkinson's disease. Brain 134(Pt 8): 2302-2311, 2011.

22. Dinkova-Kostova AT and Talalay P. Direct and indirect antioxidant properties of inducers of cytoprotective proteins. Mol Nutr Food Res 52 Suppl 1: S128-S138, 2008.

23. Freitas AE, Egea J, Buendia I, Gomez-Rangel V, Parada E, Navarro E, Casas AI, Wojnicz A, Ortiz JA, Cuadrado A, Ruiz-Nuno A, Rodrigues AL, and Lopez MG. Agmatine, by Improving Neuroplasticity Markers and Inducing Nrf2, Prevents Corticosterone-Induced Depressive-Like Behavior in Mice. Mol Neurobiol 2015 [Epub ahead of print]; DOI: 10.1007/s12035-015-9182-6.

24. Gan L, Vargas MR, Johnson DA, and Johnson JA. Astrocyte-specific overexpression of Nrf2 delays motor pathology and synuclein aggregation throughout the CNS in the alpha-synuclein mutant (A53T) mouse model. $J$ Neurosci 32: 17775-17787, 2012. 
25. Gillard GO, Collette B, Anderson J, Chao J, Scannevin RH, Huss DJ, and Fontenot JD. DMF, but not other fumarates, inhibits NF-kappaB activity in vitro in an Nrf2-independent manner. J Neuroimmunol 283: 74-85, 2015.

26. Gundersen HJ and Jensen EB. The efficiency of systematic sampling in stereology and its prediction. J Microsc 147: 229-263, 1987.

27. Hayes JD and Dinkova-Kostova AT. The Nrf2 regulatory network provides an interface between redox and intermediary metabolism. Trends Biochem Sci 39: 199-218, 2014.

28. Hayes JD, McMahon M, Chowdhry S, and DinkovaKostova AT. Cancer chemoprevention mechanisms mediated through the Keap1-Nrf2 pathway. Antioxid Redox Signal 13: 1713-1748, 2010.

29. Innamorato NG, Rojo AI, Garcia-Yague AJ, Yamamoto M, de Ceballos ML, and Cuadrado A. The transcription factor Nrf2 is a therapeutic target against brain inflammation. $J$ Immunol 181: 680-689, 2008.

30. Ishii T, Itoh K, Ruiz E, Leake DS, Unoki H, Yamamoto M, and Mann GE. Role of Nrf2 in the regulation of CD36 and stress protein expression in murine macrophages: activation by oxidatively modified LDL and 4-hydroxynonenal. Circ Res 94: 609-616, 2004.

31. Itoh K, Chiba T, Takahashi S, Ishii T, Igarashi K, Katoh Y, Oyake T, Hayashi N, Satoh K, Hatayama I, Yamamoto M, and Nabeshima Y. An Nrf2/small Maf heterodimer mediates the induction of phase II detoxifying enzyme genes through antioxidant response elements. Biochem Biophys Res Commun 236: 313-322, 1997.

32. Jain A, Lamark T, Sjottem E, Larsen KB, Awuh JA, Overvatn A, McMahon M, Hayes JD, and Johansen T. p62/ SQSTM1 is a target gene for transcription factor NRF2 and creates a positive feedback loop by inducing antioxidant response element-driven gene transcription. J Biol Chem 285: 22576-22591, 2010.

33. Jazwa A and Cuadrado A. Targeting heme oxygenase-1 for neuroprotection and neuroinflammation in neurodegenerative diseases. Curr Drug Targets 11: 1517-1531, 2010.

34. Jazwa A, Rojo AI, Innamorato NG, Hesse M, FernandezRuiz J, and Cuadrado A. Pharmacological targeting of the transcription factor Nrf2 at the basal ganglia provides disease modifying therapy for experimental parkinsonism. Antioxid Redox Signal 14: 2347-2360, 2011.

35. Jing X, Shi H, Zhang C, Ren M, Han M, Wei X, Zhang X, and Lou $H$. Dimethyl fumarate attenuates 6-OHDAinduced neurotoxicity in SH-SY5Y cells and in animal model of Parkinson's disease by enhancing Nrf2 activity. Neuroscience 286: 131-140, 2015.

36. Jo C, Kim S, Cho SJ, Choi KJ, Yun SM, Koh YH, Johnson GV, and Park SI. Sulforaphane induces autophagy through ERK activation in neuronal cells. FEBS Lett 588: 30813088, 2014.

37. Johnson DA and Johnson JA. Nrf2-a therapeutic target for the treatment of neurodegenerative diseases. Free Radic Biol Med 88: 253-267, 2015.

38. Kageyama S, Sou YS, Uemura T, Kametaka S, Saito T, Ishimura R, Kouno T, Bedford L, Mayer RJ, Lee MS, Yamamoto M, Waguri S, Tanaka $\mathrm{K}$, and Komatsu M. Proteasome dysfunction activates autophagy and the Keap1-Nrf2 pathway. J Biol Chem 289: 24944-24955, 2014.

39. Kaidery NA, Banerjee R, Yang L, Smirnova NA, Hushpulian DM, Liby KT, Williams CR, Yamamoto M, Kensler TW, Ratan RR, Sporn MB, Beal MF, Gazaryan IG, and Thomas B. Targeting Nrf2-mediated gene transcription by extremely potent synthetic triterpenoids attenuate dopaminergic neurotoxicity in the MPTP mouse model of Parkinson's disease. Antioxid Redox Signal 18: 139-157, 2013.

40. Kanninen K, Heikkinen R, Malm T, Rolova T, Kuhmonen S, Leinonen H, Yla-Herttuala S, Tanila H, Levonen AL, Koistinaho M, and Koistinaho J. Intrahippocampal injection of a lentiviral vector expressing Nrf2 improves spatial learning in a mouse model of Alzheimer's disease. Proc Natl Acad Sci U S A 106: 16505-16510, 2009.

41. Komatsu M, Kurokawa H, Waguri S, Taguchi K, Kobayashi A, Ichimura Y, Sou YS, Ueno I, Sakamoto A, Tong KI, Kim M, Nishito Y, Iemura S, Natsume T, Ueno T, Kominami E, Motohashi H, Tanaka K, and Yamamoto M. The selective autophagy substrate p62 activates the stress responsive transcription factor Nrf2 through inactivation of Keap1. Nat Cell Biol 12: 213-223, 2010.

42. Kugler S, Meyn L, Holzmuller H, Gerhardt E, Isenmann S, Schulz JB, and Bahr M. Neuron-specific expression of therapeutic proteins: evaluation of different cellular promoters in recombinant adenoviral vectors. Mol Cell Neurosci 17: 78-96, 2001.

43. Kwak MK and Kensler TW. Induction of $26 \mathrm{~S}$ proteasome subunit PSMB5 by the bifunctional inducer 3methylcholanthrene through the Nrf2-ARE, but not the AhR/Arnt-XRE, pathway. Biochem Biophys Res Commun 345: 1350-1357, 2006.

44. Lastres-Becker I, Innamorato NG, Jaworski T, Rabano A, Kugler S, Van Leuven F, and Cuadrado A. Fractalkine activates NRF2/NFE2L2 and heme oxygenase 1 to restrain tauopathy-induced microgliosis. Brain 137: 78-91, 2014.

45. Lastres-Becker I, Ulusoy A, Innamorato NG, Sahin G, Rabano A, Kirik D, and Cuadrado A. alpha-Synuclein expression and Nrf2 deficiency cooperate to aggravate protein aggregation, neuronal death and inflammation in earlystage Parkinson's disease. Hum Mol Genet 21: 3173-3192, 2012.

46. Lau A, Wang XJ, Zhao F, Villeneuve NF, Wu T, Jiang T, Sun Z, White E, and Zhang DD. A noncanonical mechanism of Nrf2 activation by autophagy deficiency: direct interaction between Keap1 and p62. Mol Cell Biol 30: 3275-3285, 2010.

47. Martin-de-Saavedra MD, Budni J, Cunha MP, GomezRangel V, Lorrio S, Del Barrio L, Lastres-Becker I, Parada E, Tordera RM, Rodrigues AL, Cuadrado A, and Lopez MG. Nrf2 participates in depressive disorders through an anti-inflammatory mechanism. Psychoneuroendocrinology 38: 2010-2022, 2013.

48. Mena MA, Pardo B, Paino CL, and De Yebenes JG. Levodopa toxicity in foetal rat midbrain neurones in culture: modulation by ascorbic acid. Neuroreport 4: 438-440, 1993.

49. Motohashi $\mathrm{H}$ and Yamamoto M. Nrf2-Keap1 defines a physiologically important stress response mechanism. Trends Mol Med 10: 549-557, 2004.

50. Parkinson Study Group QEI, Beal MF, Oakes D, Shoulson I, Henchcliffe C, Galpern WR, Haas R, Juncos JL, Nutt JG, Voss TS, Ravina B, Shults CM, Helles K, Snively V, Lew MF, Griebner B, Watts A, Gao S, Pourcher E, Bond L, Kompoliti K, Agarwal P, Sia C, Jog M, Cole L, Sultana M, Kurlan R, Richard I, Deeley C, Waters CH, Figueroa A, Arkun A, Brodsky M, Ondo WG, Hunter CB, JimenezShahed J, Palao A, Miyasaki JM, So J, Tetrud J, Reys L, Smith K, Singer C, Blenke A, Russell DS, Cotto C, Friedman JH, Lannon M, Zhang L, Drasby E, Kumar R, 
Subramanian T, Ford DS, Grimes DA, Cote D, Conway J, Siderowf AD, Evatt ML, Sommerfeld B, Lieberman AN, Okun MS, Rodriguez RL, Merritt S, Swartz CL, Martin WR, King P, Stover N, Guthrie S, Watts RL, Ahmed A, Fernandez HH, Winters A, Mari Z, Dawson TM, Dunlop B, Feigin AS, Shannon B, Nirenberg MJ, Ogg M, Ellias SA, Thomas CA, Frei K, Bodis-Wollner I, Glazman S, Mayer T, Hauser RA, Pahwa R, Langhammer A, Ranawaya R, Derwent L, Sethi KD, Farrow B, Prakash R, Litvan I, Robinson A, Sahay A, Gartner M, Hinson VK, Markind S, Pelikan M, Perlmutter JS, Hartlein J, Molho E, Evans S, Adler CH, Duffy A, Lind M, Elmer L, Davis K, Spears J, Wilson S, Leehey MA, Hermanowicz N, Niswonger S, Shill HA, Obradov S, Rajput A, Cowper M, Lessig S, Song D, Fontaine D, Zadikoff C, Williams K, Blindauer KA, Bergholte J, Propsom CS, Stacy MA, Field J, Mihaila D, Chilton M, Uc EY, Sieren J, Simon DK, Kraics L, Silver A, Boyd JT, Hamill RW, Ingvoldstad C, Young J, Thomas K, Kostyk SK, Wojcieszek J, Pfeiffer RF, Panisset M, Beland M, Reich SG, Cines M, Zappala N, Rivest J, Zweig R, Lumina LP, Hilliard CL, Grill S, Kellermann M, Tuite P, Rolandelli S, Kang UJ, Young J, Rao J, Cook MM, Severt L, and Boyar K. A randomized clinical trial of high-dosage coenzyme Q10 in early Parkinson disease: no evidence of benefit. JAMA Neurol 71: 543-552, 2014.

51. Paxinos G and Franklin KBJ. The Mouse Brain in Stereotaxic Coordinates Amsterdam; Boston: Elsevier Academic Press, 2004.

52. Pekovic-Vaughan V, Gibbs J, Yoshitane H, Yang N, Pathiranage D, Guo B, Sagami A, Taguchi K, Bechtold D, Loudon A, Yamamoto M, Chan J, van der Horst GT, Fukada Y, and Meng QJ. The circadian clock regulates rhythmic activation of the NRF2/glutathione-mediated antioxidant defense pathway to modulate pulmonary fibrosis. Genes Dev 28: 548-560, 2014.

53. Prieto $\mathrm{P}$, Rosales-Mendoza CE, Terron V, Toledano V, Cuadrado A, Lopez-Collazo E, Bannenberg G, Martin-Sanz P, Fernandez-Velasco M, and Bosca L. Activation of autophagy in macrophages by pro-resolving lipid mediators. Autophagy 11: 1729-1744, 2015.

54. Ramsey CP, Glass CA, Montgomery MB, Lindl KA, Ritson GP, Chia LA, Hamilton RL, Chu CT, and Jordan-Sciutto KL. Expression of Nrf2 in neurodegenerative diseases. $J$ Neuropathol Exp Neurol 66: 75-85, 2007.

55. Rojo AI, Innamorato NG, Martin-Moreno AM, De Ceballos ML, Yamamoto M, and Cuadrado A. Nrf2 regulates microglial dynamics and neuroinflammation in experimental Parkinson's disease. Glia 58: 588-598, 2010.

56. Rojo AI, McBean G, Cindric M, Egea J, Lopez MG, Rada $\mathrm{P}$, Zarkovic N, and Cuadrado A. Redox control of microglial function: molecular mechanisms and functional significance. Antioxid Redox Signal 21: 1766-1801, 2014.

57. Rojo AI, Salinas M, Martin D, Perona R, and Cuadrado A. Regulation of $\mathrm{Cu} / \mathrm{Zn}$-superoxide dismutase expression via the phosphatidylinositol 3 kinase/Akt pathway and nuclear factor-kappaB. J Neurosci 24: 7324-7334, 2004.

58. Rostami-Yazdi M, Clement B, Schmidt TJ, Schinor D, and Mrowietz U. Detection of metabolites of fumaric acid esters in human urine: implications for their mode of action. $J$ Invest Dermatol 129: 231-234, 2009.

59. Ruggieri S, Tortorella C, and Gasperini C. Pharmacology and clinical efficacy of dimethyl fumarate (BG-12) for treatment of relapsing-remitting multiple sclerosis. Ther Clin Risk Manag 10: 229-239, 2014.
60. Rushmore TH, Morton MR, and Pickett CB. The antioxidant responsive element. Activation by oxidative stress and identification of the DNA consensus sequence required for functional activity. J Biol Chem 266: 11632-11639, 1991.

61. Schipper HM, Liberman A, and Stopa EG. Neural heme oxygenase-1 expression in idiopathic Parkinson's disease. Exp Neurol 150: 60-68, 1998.

62. Schmidt HH, Stocker R, Vollbracht C, Paulsen G, Riley DP, Daiber A, and Cuadrado A. Antioxidants in Translational Medicine. Antioxid Redox Signal 23: 1130-1143, 2015.

63. Seidel $\mathrm{P}$ and Roth $\mathrm{M}$. Anti-inflammatory dimethylfumarate: a potential new therapy for asthma? Mediators Inflamm 2013: 875403, 2013.

64. Stefanis L. alpha-Synuclein in Parkinson's disease. Cold Spring Harb Perspect Med 2: a009399, 2012.

65. Suganuma H, Fahey JW, Bryan KE, Healy ZR, and Talalay P. Stimulation of phagocytosis by sulforaphane. Biochem Biophys Res Commun 405: 146-151, 2011.

66. Tanji K, Odagiri S, Miki Y, Maruyama A, Nikaido Y, Mimura J, Mori F, Warabi E, Yanagawa T, Ueno S, Itoh K, and Wakabayashi K. p62 Deficiency Enhances alphaSynuclein Pathology in Mice. Brain Pathol 25: 552-564, 2015.

67. Taschenberger G, Garrido M, Tereshchenko Y, Bahr M, Zweckstetter M, and Kugler S. Aggregation of alphaSynuclein promotes progressive in vivo neurotoxicity in adult rat dopaminergic neurons. Acta Neuropathol 123: 671-683, 2012.

68. Tobon-Velasco JC, Vazquez-Victorio G, Macias-Silva M, Cuevas E, Ali SF, Maldonado PD, Gonzalez-Trujano ME, Cuadrado A, Pedraza-Chaverri J, and Santamaria A. S-allyl cysteine protects against 6-hydroxydopamine-induced neurotoxicity in the rat striatum: involvement of Nrf2 transcription factor activation and modulation of signaling kinase cascades. Free Radic Biol Med 53: 1024-1040, 2012.

69. Tsianakas A, Herzog S, Landmann A, Patsinakidis N, Perusquia Ortiz AM, Bonsmann G, Luger TA, and Kuhn A. Successful treatment of discoid lupus erythematosus with fumaric acid esters. J Am Acad Dermatol 71: e15-e17, 2014.

70. van Muiswinkel FL, de Vos RA, Bol JG, Andringa G, Jansen Steur EN, Ross D, Siegel D, and Drukarch B. Expression of $\mathrm{NAD}(\mathrm{P}) \mathrm{H}$ :quinone oxidoreductase in the normal and Parkinsonian substantia nigra. Neurobiol Aging 25: 1253-1262, 2004.

71. von Otter M, Bergstrom P, Quattrone A, De Marco EV, Annesi G, Soderkvist P, Wettinger SB, Drozdzik M, Bialecka M, Nissbrandt H, Klein C, Nilsson M, Hammarsten $\mathrm{O}$, Nilsson $\mathrm{S}$, and Zetterberg $\mathrm{H}$. Genetic associations of Nrf2-encoding NFE2L2 variants with Parkinson's disease a multicenter study. BMC Med Genet 15: 131, 2014.

72. von Otter M, Landgren S, Nilsson S, Celojevic D, Bergstrom P, Hakansson A, Nissbrandt H, Drozdzik M, Bialecka M, Kurzawski M, Blennow $K$, Nilsson $M$, Hammarsten O, and Zetterberg H. Association of Nrf2encoding NFE2L2 haplotypes with Parkinson's disease. BMC Med Genet 11: 36, 2010.

73. Wang YY, Yang YX, Zhe H, He ZX, and Zhou SF. Bardoxolone methyl (CDDO-Me) as a therapeutic agent: an update on its pharmacokinetic and pharmacodynamic properties. Drug Des Devel Ther 8: 2075-2088, 2014.

74. Watanabe Y, Tatebe H, Taguchi K, Endo Y, Tokuda T, Mizuno T, Nakagawa M, and Tanaka M. p62/SQSTM1dependent autophagy of Lewy body-like alpha-synuclein inclusions. PLoS One 7: e52868, 2012. 
75. Wilms H, Sievers J, Rickert U, Rostami-Yazdi M, Mrowietz U, and Lucius R. Dimethylfumarate inhibits microglial and astrocytic inflammation by suppressing the synthesis of nitric oxide, IL-1beta, TNF-alpha and IL-6 in an in-vitro model of brain inflammation. $J$ Neuroinflammation 7: 30, 2010.

76. Xilouri M, Brekk OR, and Stefanis L. alpha-Synuclein and protein degradation systems: a reciprocal relationship. Mol Neurobiol 47: 537-551, 2013.

77. Yamazaki H, Tanji K, Wakabayashi K, Matsuura S, and Itoh K. Role of the Keap1/Nrf2 pathway in neurodegenerative diseases. Pathol Int 65: 210-219, 2015.

78. Yoo MS, Chun HS, Son JJ, DeGiorgio LA, Kim DJ, Peng $\mathrm{C}$, and Son JH. Oxidative stress regulated genes in nigral dopaminergic neuronal cells: correlation with the known pathology in Parkinson's disease. Brain Res Mol Brain Res 110: 76-84, 2003.

79. Zhang Z, Wang S, Zhou S, Yan X, Wang Y, Chen J, Mellen N, Kong M, Gu J, Tan Y, Zheng Y, and Cai L. Sulforaphane prevents the development of cardiomyopathy in type 2 diabetic mice probably by reversing oxidative stressinduced inhibition of LKB1/AMPK pathway. J Mol Cell Cardiol 77: 42-52, 2014.

$$
\begin{array}{r}
\text { Address correspondence to: } \\
\text { Dr. Antonio Cuadrado } \\
\text { Instituto de Investigaciones Biomédicas } \\
\text { "Alberto Sols" UAM-CSIC } \\
\text { C/Arturo Duperier } 4 \\
\text { Madrid 28029 } \\
\text { Spain }
\end{array}
$$
E-mail: antonio.cuadrado@uam.es
Dr. Isabel Lastres-Becker Instituto de Investigaciones Biomédicas "Alberto Sols" UAM-CSIC C/Arturo Duperier 4 Madrid 28029

Spain

E-mail: ilbecker@iib.uam.es

Date of first submission to ARS Central, October 20, 2015; date of final revised submission, March 17, 2016; date of acceptance, March 22, 2016.

$\begin{aligned} & \text { Abbreviations Used } \\ \mathrm{DA} & =\text { dopamine } \\ \mathrm{DAPI} & =4^{\prime}, 6 \text {-diamidino-2-phenylindole } \\ \mathrm{DMEM} & =\text { Dulbecco's modified Eagle's medium } \\ \mathrm{DMF} & =\text { dimethyl fumarate } \\ \mathrm{DOPAC} & =3 \text {, } 4 \text {-dihydroxyphenylacetic acid } \\ \mathrm{HO}-1 & =\text { heme oxygenase- } 1 \\ \mathrm{MMF} & =\text { monomethyl fumarate } \\ \mathrm{NQO} 1 & =\text { NADPH quinone oxidoreductase } 1 \\ \mathrm{PD} & =\text { Parkinson's disease } \\ \mathrm{qRT}-\mathrm{PCR} & =\text { quantitative real-time polymerase chain } \\ \mathrm{SN} & =\text { reaction } \\ \mathrm{TH} & =\text { tyrosine hydroxylase } \\ \mathrm{VMB} & =\text { ventral midbrain }\end{aligned}$

